\title{
FAMILIA, PODER Y ESMERALDAS. \\ Relaciones de género y estructura económica minera en el occidente de Boyacá, Colombia
}

\section{Johanna A. PARra Bautista}

Estudiante de doctorado en antropología social, Centro de Investigaciones y Estudios Superiores de Antropología Social (Ciesas), México, y del Laboratorio de Etnología y Sociología Comparada, Paris X-Nanterre.

j.parrab@gmail.com

A doña Lola

\section{Resumen}

A ORGANIZACIÓN SOCIAL Y CULTURAL DE LA ZONA ESMERALDÍFERA DEL OCCIDENTE DEL Lepartamento de Boyacá (Colombia) está relacionada con los insumos de la producción minera, que se reflejan en las transformaciones de las estructuras de parentesco y las adaptaciones de la familia. Este artículo expone una aproximación etnográfica al complejo familiar de la región, con el objeto de comprender la incidencia de las jerarquías en las relaciones de género y en la crianza de los hijos. Por medio del texto se presenta el poder masculino como acción de dominio de medios de producción, y el control femenino como relaciones con otros miembros de la familia nuclear y extensa.

PALABRAS ClAVE: minería, esmeraldas, parentesco, relaciones de género, familia, Boyacá.

\section{Abstract}

T HE SOCIAL AND CULTURAL ORGANIZATION IN THE EMERALD PRODUCING REGION OF THE department of Boyacá is related to mining production, which has in itself transformed kinship and family structures. Using an ethnographic approach to examine family structures in the region, the article seeks to demonstrate the incidence of hierarchies in gender relations and child raising. I argue that masculine power is exercised through dominance over the modes of production while feminine control is apparent in the relations with other members of the nuclear and extended family.

KEY WORDS: Mining communities, emeralds, kinship, gender relations, Boyaca.

$\frac{\text { Revista Colombianade Antropología }}{\text { Volumen 42, enero-diciembre 2006, pp. } 1553}$




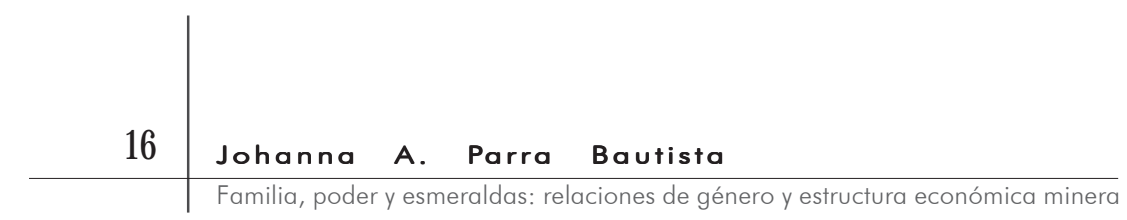

\section{INTRODUCCIÓN}

⿹ ESPUÉS DE VARIOS INTENTOS POR ESCRIBIR SOBRE LAS RELACIONES ENTRE los hombres y las mujeres cuyas vidas se desenvuelven en la producción de esmeraldas en el occidente del departamento de Boyacá (Colombia) (véase el mapa) ${ }^{1}$ en los que romanticé o victimicé a las mujeres, decidí intentarlo de nuevo²; opté en esta oportunidad por abordar las relaciones de género recreando algunos escenarios en los que interactúan hombres y mujeres ubicados en diferentes posiciones del contexto económico y social de la región. Para ello me concentro en las dinámicas de familia ${ }^{3}$, en las relaciones con las parentelas ${ }^{4} \mathrm{y}$, en la medida de lo posible, en las relaciones de pareja.

Mi objetivo es examinar y analizar el lugar de estas interacciones en el ordenamiento y la jerarquía social y de género que se ha establecido desde el inicio de la explotación de esmeraldas; en consecuencia, presto especial atención a lo que sucede en las familias oligarcas ${ }^{5}$ del occidente de Boyacá. Al describir e interpretar algunas dinámicas características de su vida íntima, busco ofrecer una interpretación sobre las relaciones sociales de género en la región, ausente hasta ahora en los estudios sobre la economía esmeraldífera y la violencia asociada a ella

1 Comprende los municipios de Maripí, Muzo, Quípama, Coscuez, San Pablo de Borbur, Otanche, Pauna, Briceño y Buena Vista.

2. Agradezco en especial a Margarita Chaves, por sus comentarios en cuanto a la redacción y el contenido, y por las lecturas que me recomendó sobre el quehacer del antropólogo. A Yaneth Pinilla por sus dedicación sus sugerencias y por su disposición para culminar este artículo.

3 Retomo la elaboración conceptual de Sierra, quien hace una síntesis completa de varias definiciones de familia y unidad doméstica. Ella articula la familia como espacio económico y lugar en el que se reproducen las "condiciones materiales que permiten la reproducción física de los individuos"; y como "esfera de la intimidad", en la que se llevan a cabo los procesos de socialización y tienen lugar las relaciones entre hombres y mujeres (Sierra, 200329

4. Me refiero a la familia extensa que comprende los parientes maternos y paternos.

5 Hablo de oligarquías por tratarse de la conformación de una élite capitalista.
(Páramo, 2003: Steiner, 2003 Uribe, 1992). Los estudios han resaltado la imbricación entre la ilegalidad, la masculinidad y la violencia, con énfasis en el tipo de relaciones que permiten el funcionamiento de una economía extractiva con un tenue margen de (i)legalidad, en el que las cuentas pendientes se saldan hasta con la vida. Su énfasis en las actuaciones masculinas, sin embargo, deja por fuera la agencia de las mujeres, que resalto en este artículo. 

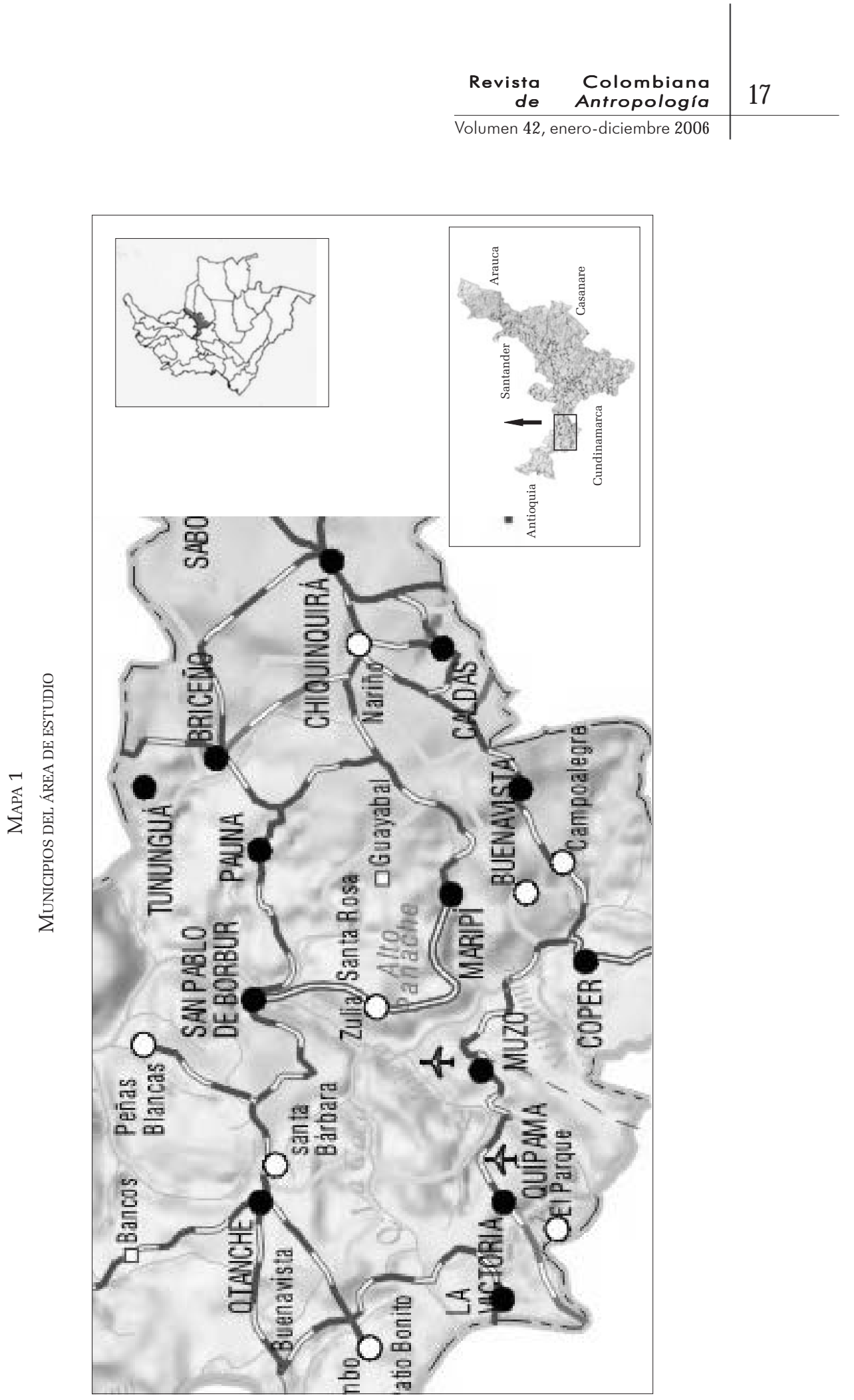


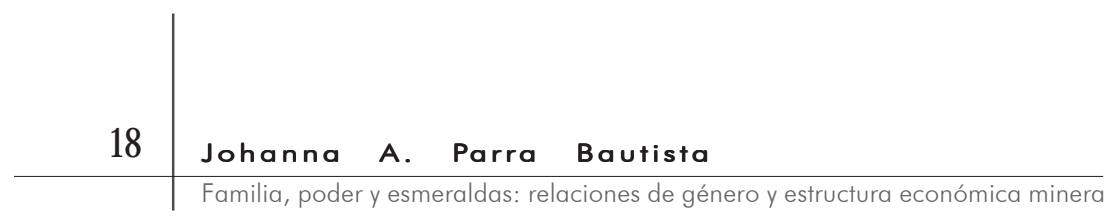

Los estudios sobre los discursos culturales que estereotipan a los esmeralderos son inexistentes también. Encajados en una suerte de "infamous ocupation" (Blok, 2001) que los condena por sus actividades, comportamientos y modas, en la sociedad urbana colombiana los esmeralderos evocan siempre imágenes de "machos violentos", "campesinos con plata", "ignorantes" y "venidos a más". Aun cuando los estudios mencionados ofrecen una aproximación al lugar en el que se genera el estereotipo de "macho" esmeraldero como "mafioso violento", no brindan muchas pistas para ubicar el de "nuevos ricos venidos a más" que suele acompañarlo. Sin pretender adentrarme en el asunto, quiero señalar que el discurso cultural para tipificar los espacios sociales y estéticos de las élites esmeralderas, la construcción del "nuevo rico emergente", se expresa desde una posición dominante que ve un exceso en el efecto mimético que buscan los esmeralderos de los gustos y las formas de vida aristocrática de las élites centrales colombianas, asociadas especialmente con los sectores urbanos de clase alta y media alta del país, especialmente de Bogotá. Sin embargo, casi nunca se ha examinado cómo la producción cultural sobre el nuevo rico esmeraldero trasluce el rechazo a su capacidad de transgredir el ordenamiento jerárquico del arriba y el abajo dentro de una estructura de clase social, gracias a su poder económico.

Busco también contribuir a diversificar esas imágenes tan arraigadas en la cultura popular colombiana sobre los agentes sociales y económicos de la explotación de esmeraldas, mostrando qué hay más allá de este tipo de representaciones, y resaltando, en particular, las transformaciones en las estructuras sociales del occidente boyacense por el desarrollo de una de las economías más importantes del país. Mi intención en este sentido es explorar algunas dinámicas de asociación y relación entre miembros de familias de esmeralderos, en las que las mujeres tienen un papel importante en el ordenamiento social, mediante el mantenimiento de la cohesión familiar y en la definición de las actuaciones de los agentes masculinos que sostienen y definen esa economía minera.

Para darle visibilidad al papel de las mujeres parto de la distinción entre poder y control planteada por Richard Adams y retomada por Roberto Varela, sugerente como premisa para el análisis. El poder, entendido como la "habilidad de lograr que alguien haga lo que usted quiere mediante el control sobre los 


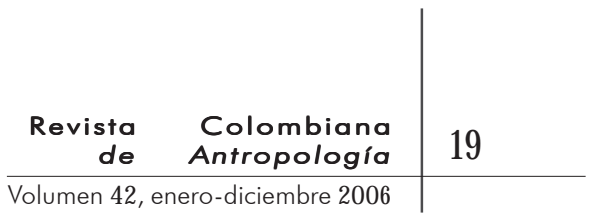

procesos energéticos ${ }^{6}$ de interés para él” (Adams, 1983 121); y el control, definido como "una relación sociopsicológica entre personas o unidades operantes capaces de razonar y decidir por sí mismas el curso de acción más conveniente en una situación concreta y definida" (Varela, 2005 129). Retomo las interpretaciones teóricas de Varela, en las que esta diferenciación nos permite hablar de seres diferentes, y aun cuando el poder se basa en el control, los actores pueden, y de hecho lo hacen, separar el control y el poder. Es decir, en el caso de estudio, la capacidad que tiene una mujer de retener el control sobre un hijo o una propiedad, y, al mismo tiempo, de transferir a otro (hombre) el derecho de decidir; o el caso del hombre que controla a sus subalternos, pero otorga a su mujer la decisión de contratar a un pariente para una relación laboral ${ }^{7}$. En ambos casos estamos frente a un poder dependiente, según las tipologías de Adams, en el que las mujeres y los hombres están en una dialéctica de poderes otorgados, cediendo a otro(a) un derecho.

En las relaciones de poder entre hombres y mujeres de esta región de explotación minera de esmeraldas, encontramos relaciones diádicas en las que se identifica siempre un patrón que ejerce poder sobre sus subordinados, entre los 6. Con procesos energéticos Adams se refiere a los recursos naturales, económicos y políticos.

7. Estos ejemplos se expondrán más extensamente a lo largo del texto. que están sus mujeres: esposa, amantes, hijas y el resto de mujeres a su servicio, entre otras su parentela femenina; sus hombres de seguridad; y sus hombres de confianza, en quienes descansan sus negocios y muchos de los cuales son, también, parte de su parentela. La relación de subordinación de cada uno de los anteriores interfiere directamente en las relaciones que los subordinados pueden establecer entre ellos mismos, tal como se describe el diagrama 1

En este diagrama $\triangle \mathrm{P}$ es un patrón y a la vez esposo de(P. Las relaciones entre ${ }_{P}$ y su hermano $\mathrm{H}$, que están al mismo nivel, aun cuando de diferentes maneras ambos son subordinados, están influidas por la relación de subordinación de $\mathrm{H}$ a $\mathrm{P}$, pues en este caso particular $\mathrm{H}$ es el hombre de confianza de $\mathrm{p}$, es decir, su subordinado. A manera de ejemplo: si H debe guardar un secreto de su patrón que pueda dañar física o moralmente a su hermana, el guardar el secreto prevalecerá sobre la relación de consanguinidad con su hermana. 


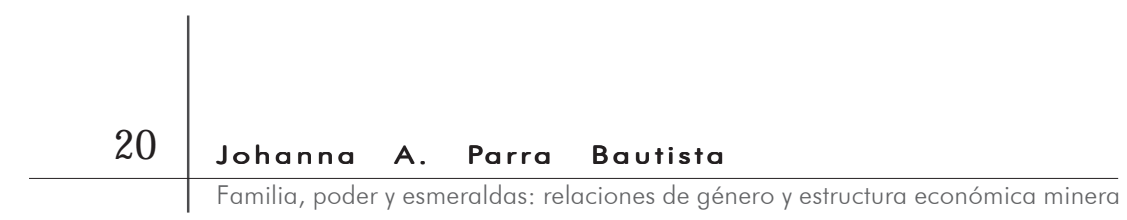

Diagrama 1

PREVALENCIA DE LA JERARQUía SOBRE LAS RELACIONES DE PARENTESCO

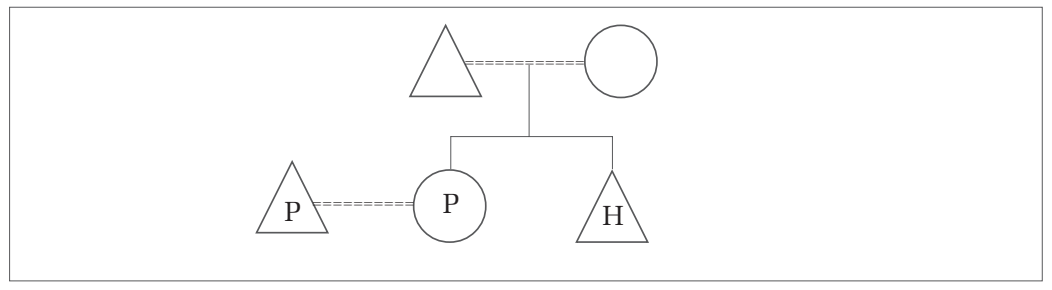

Con este análisis me propongo demostrar las relaciones de poder y control que se establecen entre estos hombres y mujeres, las cuales hacen parte de sus relaciones intra e inter géneros, es decir, de la definición de sus masculinidades y feminidades; relaciones que, por tanto, se reflejan en su vida cotidiana, en sus negocios y en la educación de los hijos. Con el propósito de describir las situaciones de poder en su complejidad recurro a la categoría de género como "elemento constitutivo de las relaciones sociales basadas en las diferencias que distinguen los sexos y como forma primaria de relaciones significativas de poder" (Scott, 1990: 2358). Los hombres, productores y detentadores de poder económico, y las mujeres, dueñas de los espacios domésticos, que controlan, entretejen, como se ve a primera vista, unas formas de dominación masculina (Bourdieu, 1998) que en el occidente de Boyacá se sobreponen, algunas veces violentamente, al poder femenino. No obstante, estamos frente a un poder femenino capaz de subvertir la dominación masculina en una prolongación de la masculinidad que reproduce también violencias de signo masculino.

Este artículo esta divido en cuatro partes. En la primera presento algunas características de la investigación y el marco metodológico. En la segunda describo rápidamente la cotidianidad campesina antes de que se iniciara la explotación esmeraldífera, para comprender los cambios de la producción y su incidencia en la vida familiar y en la unidad doméstica. En la tercera muestro las relaciones entre los hombres y las mujeres en el contexto de una economía de explotación de esmeraldas. Aquí analizo con especial atención las relaciones de familia mediante el examen de la relación entre patrones y esposas. Por último expongo algunas conclusiones orientadas a esbozar las tendencias predominantes en las estructuras regionales de parentesco y familia. 


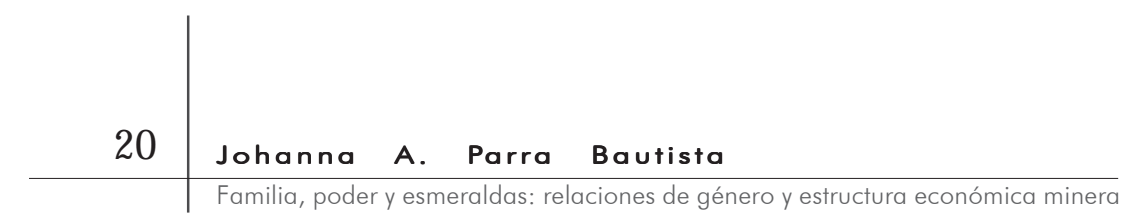

Diagrama 1

PREVALENCIA DE LA JERARQUía SOBRE LAS RELACIONES DE PARENTESCO

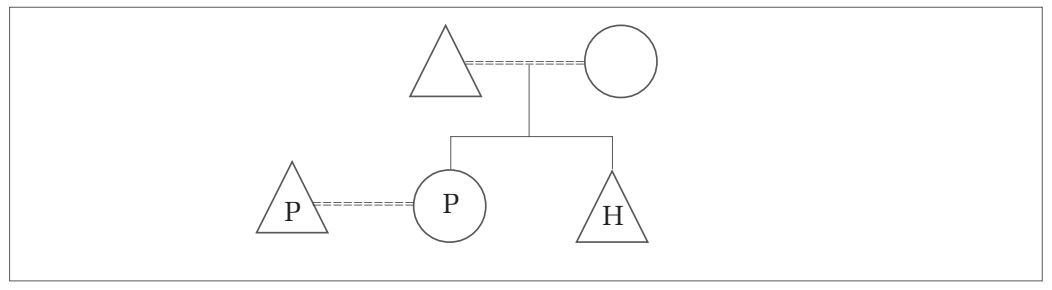

Con este análisis me propongo demostrar las relaciones de poder y control que se establecen entre estos hombres y mujeres, las cuales hacen parte de sus relaciones intra e inter géneros, es decir, de la definición de sus masculinidades y feminidades; relaciones que, por tanto, se reflejan en su vida cotidiana, en sus negocios y en la educación de los hijos. Con el propósito de describir las situaciones de poder en su complejidad recurro a la categoría de género como "elemento constitutivo de las relaciones sociales basadas en las diferencias que distinguen los sexos y como forma primaria de relaciones significativas de poder" (Scott, 1990: 2358). Los hombres, productores y detentadores de poder económico, y las mujeres, dueñas de los espacios domésticos, que controlan, entretejen, como se ve a primera vista, unas formas de dominación masculina (Bourdieu, 1998) que en el occidente de Boyacá se sobreponen, algunas veces violentamente, al poder femenino. No obstante, estamos frente a un poder femenino capaz de subvertir la dominación masculina en una prolongación de la masculinidad que reproduce también violencias de signo masculino.

Este artículo esta divido en cuatro partes. En la primera presento algunas características de la investigación y el marco metodológico. En la segunda describo rápidamente la cotidianidad campesina antes de que se iniciara la explotación esmeraldífera, para comprender los cambios de la producción y su incidencia en la vida familiar y en la unidad doméstica. En la tercera muestro las relaciones entre los hombres y las mujeres en el contexto de una economía de explotación de esmeraldas. Aquí analizo con especial atención las relaciones de familia mediante el examen de la relación entre patrones y esposas. Por último expongo algunas conclusiones orientadas a esbozar las tendencias predominantes en las estructuras regionales de parentesco y familia. 


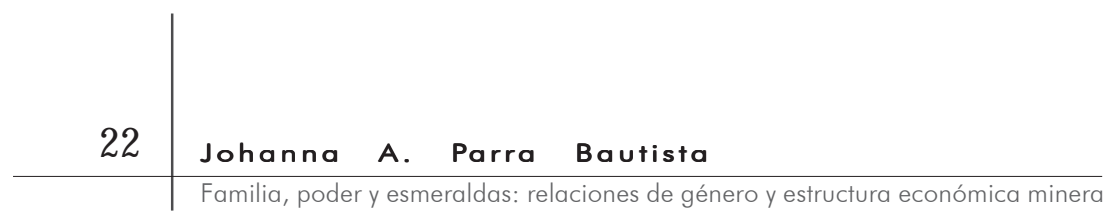

algunas ferias municipales organizadas por mujeres, espacios en donde pude observar con más claridad las jerarquías entre patrones y familias.

En general, la interlocución con los hombres fue más difícil que con las mujeres, debido a su hermetismo y desconfianza con agentes externos a sus negocios. Si bien a ellos no los entrevisté sobre el asunto de las relaciones de género, siempre estuvieron dispuestos a hablar sobre sus trayectorias laborales y acerca de la historia de la región y de las minas. Todos los nombres de lugares y personas fueron cambiados para proteger la privacidad de los entrevistados.

\section{Memoria de los abuelos. DE UNA ECONOMÍA AGRÍCOLA A UNA DE EXTRACCIÓN DE ESMERALDAS}

C IEMPRE QUE TUVE LA OPORTUNIDAD DE CONVERSAR CON DOÑA LOLA, una mujer nacida en 1930, en la vereda El Milagro, me habló de $\checkmark$ sus días antes de la explotación minera. Más que para responder a mis preguntas, recreaba la tristeza que sentía por la pérdida de su marido, asesinado en la década de $\mathbf{1 9 5 0}$ después de un ajuste de cuentas entre liberales y conservadores. Sus relatos constituyen una voz nostálgica y romántica que revive en la memoria la cotidianidad de una época que quedó enterrada bajo la tierra negra de las minas. Además de las descripciones de la vida campesina y de las dimensiones de un temporalidad perdida -sus largas jornadas para desplazarse de su rancho a la cabecera municipal, o la travesía en mula y tren la única vez que su padre la llevó a la capital-, lo que más me llamaba la atención en sus relatos era el amor que a través de ellos profesaba por su difunto marido. Aún cincuenta años después de su muerte, doña Lola secaba sus lágrimas porque él no había podido ver a los hijos crecer, ni la belleza de la huerta y de las panelas fabricadas con la caña de aquella cosecha. Al escucharla pensaba en lo extrañas que resultaban sus palabras, comparadas con las que expresan los sentimientos de muchas mujeres jóvenes de hoy por sus maridos. A más de una de ellas la escuché decir que preferirían verlos muertos para enviudar y así liberarse del yugo de su dominancia, término con el que se refieren a la dominación que ejercen sobre ellas. 


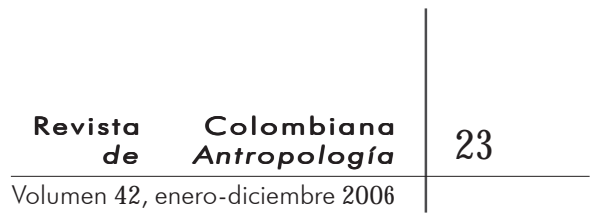

Los relatos de esas mujeres, que en 2002 tenían entre sesenta y setenta años, son la evidencia de una armonía, no sé hasta que punto idealizada, que las parejas intentaban recrear en sus hogares, ensombrecida eventualmente por la muerte de algunos menores, debido a la desatención médica o a la carencia de recursos familiares para atender una emergencia. En las escenas que puedo recrear a partir de sus relatos, las protagonistas eran mujeres muy jóvenes cuando se casaron por la iglesia católica, tuvieron entre cinco y diez hijos, y vivieron por largo tiempo en sus ranchos en las áreas rurales veredales, antes de trasladarse a las cabeceras municipales. Estas abuelas compartieron hombro a hombro con sus esposos las labores domésticas y de agricultura. En la crianza los varones tenían prioridad para asistir a la escuela, pues las mujeres se debían encargar de las labores domésticas, en especial de preparar alimentos para la familia y los trabajadores de las fincas. Este fragmento pertenece a un relato hecho por doña Carmela, de setenta y seis años, quien describe estas situaciones:

\begin{abstract}
Nosotros, mi esposo y yo, nacimos en una vereda, cerca de aquí. En ese tiempo [años 1950] teníamos nuestro rancho. Nos levantábamos temprano para hacer el trabajo del ranchito, a la parcela a trabajar los dos, sembrábamos lo de comer, nunca faltó la comida. La carne la comprábamos los domingos en el pueblo, íbamos caminando y llevábamos la mula para llevar unos guineos y colí [variedades de plátano] para vender. Para ir a la ciudad íbamos en mula, hacíamos un día de camino, parábamos en el alto a comer papas o alguna sopita que nos vendieran y así. Después, con los niños, él colaboraba y cuando crecieron trabajaban con nosotros en agricultura, cocinando para los obreros. (...) Son mis hijos más menores los que después les gustó la mina y allá están.
\end{abstract}

Hasta los años 1950, el occidente de Boyacá fue sobre todo un territorio de producción agrícola, fortín y área de aprovisionamiento y tránsito de bandoleros como Efraín González ${ }^{9}$, una suerte de héroe en la región, bandoleros que circulaban por la zona en sus an-

9. Este bandolero pasó de militar a bandolero para vengar la muerte de su familia, a la que, según la historia oral, asesinaron en presencia suya de manera atroz. Su historia es objeto de múltiples versiones y está en la base de la elaboración de discursos sobre la identidad masculina regional, mezcla de héroe, guerrero, luchador y minero (véase Téllez, 1987). danzas entre Santander y la capital del país. A partir de 1960, cuando se inició la explotación de las minas de Peñas Blancas y 


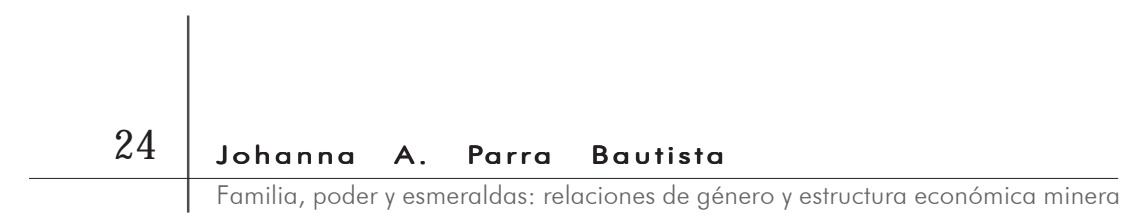

posteriormente la de Muzo, la minería se convirtió en una alternativa muy atractiva para los campesinos que hasta entonces vivían de una economía de pancoger. La explotación minera cambió por completo el proceso de poblamiento y atrajo una inmensa población flotante, compuesta casi exclusivamente de varones (Uribe, 1992: 6186). Trabajadores provenientes de todas las regiones del país se vincularon al trabajo en las minas, pero entre ellos hubo una concentración especial de varones de los llanos orientales, quienes años más tarde regresaron a su región de origen a comprar tierras.

La transición de una economía agrícola a una minera se hizo mediante la combinación de formas tradicionales de asociación para la producción agrícola y de vida familiar campesina con relaciones propias de una economía extractiva, en la que las relaciones sociales de producción movilizaban grandes cantidades de dinero representadas en esmeraldas. Esta articulación de lógicas de producción tan divergentes se puede interpretar por medio del concepto de "embededdness" (Bourdieu, 2000: 17), es decir, del énfasis en la incrustación histórica y cultural de las relaciones sociales en la historia y en la estructura. En la medida en que la economía no es una isla en la realidad social, sino que está profundamente asentada en ella y tiene consecuencias sobre la misma, el "embededdness" es una noción próxima al concepto de "hecho social total" de Marcel Mauss, útil para comprender las relaciones de poder y de género que se establecen en el marco de la economía de las esmeraldas. Este concepto nos permite examinar, por ejemplo, los cambios que se producen o no en las relaciones sociales en general, y de género en particular, en un contexto de transformación económica radical como en el que generó la explotación de un recurso minero de alto valor en el mercado. La abrupta intervención de este recurso económico en la población no permitió que las relaciones sociales se transformaran a la misma velocidad con la que se implantó la nueva estructura productiva, por lo que en las adaptaciones que suceden con este cambio abrupto afloran dimensiones culturales históricas de arraigo.

En los años 1960, la explotación de esmeraldas en el occidente de Boyacá produjo, entre otros cambios, la oferta de nuevos trabajos en la mina y alrededor de ella. Esto hizo que familias enteras trasladaran el lugar de su residencia de las áreas rurales a los barrios que comenzaron a formarse cerca a las minas, y en 


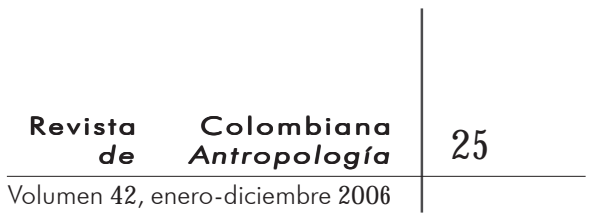

la mayoría de los casos llevó a la ausencia de los varones de los hogares durante largas temporadas. Ambos procesos condujeron a la reorganización de los roles masculinos y femeninos relacionados con el espacio doméstico. Me atrevo a sugerir que si en el periodo de producción agrícola que retratan las narrativas de las abuelas se puede percibir una unidad doméstica conformada por padres e hijos, incluidas las mujeres, que trabajaban sus propias parcelas para el consumo doméstico, en la nueva economía de extracción es necesaria la unificación de la parentela, es decir, de un número importante de integrantes de la familia extensa que entran en la actividad productiva alrededor de un núcleo, que siempre está representado por el hombre más próspero. Me refiero a una nueva división de labores que incluye a la parentela y en la que la asignación de la actividad de cada integrante dependerá tanto de su posición en el parentesco como del desarrollo de sus relaciones de confianza con el patrón.

No obstante el auge económico alcanzado por muchos de sus hijos en la mina, las mujeres de esta generación, es decir, las abuelas de hoy, continuaron llevando un modo de vida campesino; siguieron trabajando la finca, criando animales y manteniendo algunos sembrados, a pesar de la escasa oferta de mano de obra masculina para esas labores. Los cambios a su alrededor no afectaron su estatus; por el contrario, dada la alta valoración que los varones le otorgan al papel de la madre, hoy por hoy las mujeres de edad son figuras de primer orden en la nueva sociedad, tanto que su papel de madres se sobrepone al de las esposas. Ellas tienen acceso directo y permanente a sus hijos, sin importar dónde se encuentren, además de toda su consideración. Pero mientras ellas continuaron con sus tradiciones campesinas sus hijas han experimentado rupturas drásticas con los ritmos y los estilos de vida anterior, en especial con las relaciones de simetría que sus madres alcanzaron con los esposos. Ahora bien, es importante destacar que muchas de las actuales abuelas son viudas; y es poco lo que se comenta de ellos más allá de su amor por el trabajo. Así, a la nostalgia de las abuelas por los tiempos pasados se suma, entonces, su preocupación por el sufrimiento de sus hijas en sus matrimonios, aspecto que trataré a continuación. 


\section{EL SURGIMIENTO DE UN PODER LOCAL.} BIENVENIDO EL ZAR

...que la guerra de esta región es guerra de poderes. Que el que más plata tiene, más armas compra y más hombres tiene. Eso es una cosa muy natural, y eso lo sé yo y lo sabe el gobierno...

Chucho, Control del corte de Puerto Yori.

$\wedge$ DEMÁS DE LOS CAMBIOS EN LAS RELACIONES FAMILIARES Y DE GÉNERO provocados por el tránsito de la economía campesina a una de minería extractiva de características tan peculiares como la de las esmeraldas, condicionada a ella surgió una oligarquía local que se posesionó del control de las minas y de los habitantes de la región. Su dominio fue, en parte, una respuesta a las características de la actividad minera, pero sobre todo a la debilidad del estado colombiano y a su incapacidad de administrar y controlar el creciente número de hombres armados que durante más de una década intentaron entrar a explotar las minas.

En 1963, el estado trató de controlar la situación mediante el uso de la fuerza pública. El diagrama 2 representa el tipo de dominio que las fuerzas militares intentaron imponer sobre la población trabajadora y sobre quienes deseaban entrar a la mina a trabajar en los años 1960 y comienzos de la década de 1970.

\section{Diagrama 2}

CONTROL DE LAS FUERZAS MILITARES SOBRE LOS MINEROS DURANTE LAS DÉCADAS DE 1960 y 1970

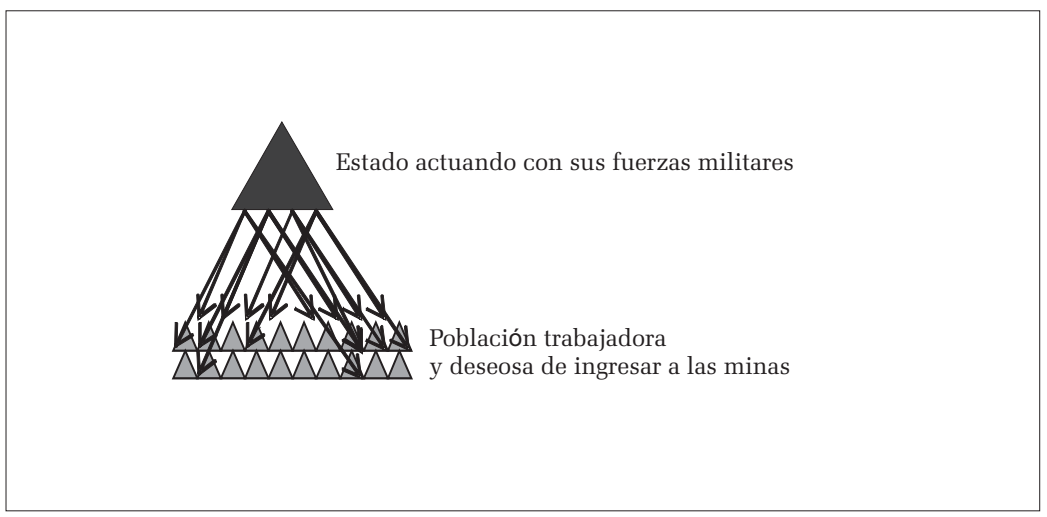




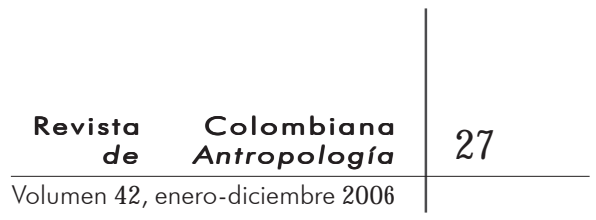

Bajo esta estructura murieron numerosas personas que intentaban infiltrarse a la mina, y hubo enfrentamientos terribles, conocidos en la región como la guerra verde. Los mineros se enfrentaron con el ejército, con el argumento de los maltratos y las medidas arbitrarias que les impedían trabajar tranquilamente, como las requisas permanentes y los juicios por robo al estado cuando lograban el blanco de una esmeralda. En 1973, el gobierno del presidente Misael Pastrana (1970-1974) decidió cerrar y militarizar las minas. El relato de Chucho $^{10}$, un trabajador de sesenta y cinco años que vivió en carne propia el rigor de esa época, sirve para comprender la relación que se estableció entonces 10. Esta entrevista fue hecha junto con Nicolás Arango Cadavid, durante una estancia en la mina de Puerto Yori, en 2003

con los organismos del estado:

Por los años 72 ó 73vino el coronel José Joaquín Matallana y ahí duró el ejército en las minas, cuidándolas, ...hasta el 21de diciembre de 1975, cuando el capitán Hugo Villalba entregó el puesto que tenía el ejército en el puente del río Minero. Uno entraba a la mina a rebuscarse y ellos no dejaban trabajar, igual uno corría el peligro, porque si lo agarraban era muerte fija. Pero había que trabajar.

El mismo obrero, al narrar la historia de una requisa en una fiesta, se refirió a la policía en los siguientes términos:

(...) A un policía uno no le tenía respeto porque ellos se hacían irrespetar. Ellos cometían los abusos. (...) Por el hecho de ser policías iban a mangonear la gente y pensaban que en la mina era como en las ciudades, que echan fuete a cualquiera, y aquí no. Aquí ellos sufrieron las consecuencias, porque aquí los mineros no permitían la desigualdad de que ellos fueran superiores; todos eran iguales (...). Tanto hombre era el policía como hombre era el civil, y si [el policía] creía que era más hombre, ipues había que probarlo! Si no querían que hubiera muertos, pues vamos a guardar las armas y nos vamos a mamoniar la cara, y si no había esa tregua, pues el policía mataba o los civiles matábamos.

En este relato se refleja la subversión al poder establecido, que avanzó rápido con la respuesta violenta de los mineros a la violencia estatal. En ella se percibe la visión que tenían los mineros de los organismos de control, como limitadores de la libertad en detrimento del bien de los individuos. La presencia del 


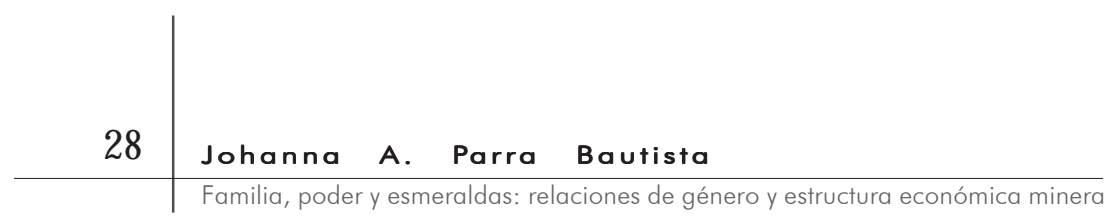

ejército se consideraba una violación a la posibilidad de trabajar. El entrevistado cuenta que cuando la policía los requisaba les decomisaba los implementos de trabajo, el cincel y el martillo, indispensables para guaquear ${ }^{11}$. Como anota María Victoria Uribe (1992), los habitantes de la región del occidente de Boyacá consideran las minas como algo propio y al estado como el enemigo que siempre pretende usurparles su explotación. Este es un elemento importante en la conformación de la mentalidad mafiosa de los jefes locales, quienes se erigieron sobre la disminución de los poderes del estado, lo cual derivó en la creación de un paraestado controlado por ellos. Es decir que a la base económica de extracción minera se sumaron procesos políticos y militares específicos de la región, que dieron paso al surgimiento y al fortalecimiento de algunas familias locales organizadas para detentar el poder local ${ }^{12}$. Me refiero a una estructura jerárquica de poder local, en la que el estatus más alto lo ocupan varios hombres llamados en la región dones o patrones, quienes dominan la explotación y el comercio de la esmeralda. Cada

11 Guaquiar. Trabajar en la mina. Guaquero. Mujer, hombre o niño que lavan la tierra en el río en busca de esmeraldas. Obrero. Hombre que trabaja en el interior de la mina, en los túneles que se abren mediante la detonación de pólvora.

12. Utilizo la caracterización de mafias de Blok, sin acomodar el concepto de mafia a las características de los poderes locales de la región estudiada (Blok, 1974: xvii).

Colombia (Emeracol), empresa conformada por un grupo de dones de la región que sobrevivieron a la guerra y quienes se convirtieron en socios del estado para cuestiones relacionadas con la explotación de esmeraldas (Steiner, 2003 8). Desde entonces, esos dones, respetados unos por su honorabilidad y otros temidos por su violencia, controlan su producción. Con el objetivo de cuidar las minas y mostrar su poder local, los patrones de cada familia crearon y mantuvieron grupos de hombres armados, los pájaros, que los acompañaban y estaban encargados de cuidar a sus familias y sus propiedades. La centralización del poder social y militar en manos de ellos desplazó al estado: hasta hoy mantienen el monopolio de la violencia y sostienen una dinámica de capitalismo rentista con base en la consolidación del control sobre el territorio y la dependencia de los campesinos que se convierten en 


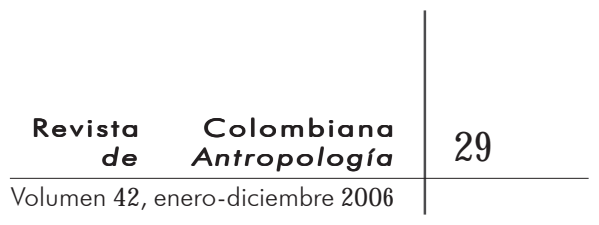

obreros de las minas. El diagrama 3muestra las relaciones de poder tras la cesión de este a los jefes locales por parte del estado. Es importante reconocer que cuando el estado les otorga el poder y el control de las minas, el territorio y la población a esos jefes, los reconoce como agentes de su mismo nivel, ya que ellos lo suplantarán en el ejercicio de sus funciones de control.

Diagrama 3

RELACIONES DE PODER LOCAL TRAS LA INTRODUCCIÓN DE LAS FAMILIAS LOCALES

\begin{tabular}{|ccc|} 
Familia extensa 1 & Familia extensa 2 & Familia extensa 3 \\
Minas 1 & Minas 2 & Minas 3 \\
Territorio 1 & Territorio 2 & Territorio 3 \\
Población 1 & Población 2 & Población 3 \\
\hline
\end{tabular}

Posteriormente hubo dos enfrentamientos muy cruentos entre jefes locales, por violaciones del honor, por el incumplimiento de la palabra empeñada ${ }^{13}$ : la primera guerra de esmeralderos, entre 1970 y 1975 y la segunda guerra, entre 1984 y 1990. Entre los patrones de la zona, costaron la vida a numerosos esmeralderos y miembros sus familias, tanto en el territorio del occidente de Boyacá como en Bogotá; así mismo, supusieron el destierro y el desplazamiento de otros. El diagrama 4 ilustra elementalmente el tipo de enfrentamientos.

Sembrado profundamente el conflicto, se firmó la paz y las familias retornaron a sus dominios. De manera paralela, tras el descubrimiento de otras minas surgieron nuevas familias y se establecieron nuevas alianzas para prevenir más enfrentamientos ${ }^{14}$. De esos enfrentamientos emergió la figura del zar de las esmeraldas, quien al salir fortalecido estableció un orden como el que describe el diagrama 5

13 "Si existe confianza, ésta emerge más de la confiabilidad de la oferta y la demanda que de algún tipo explícito de palabra empeñada, ya que, en rigor, la libertad de mercado impide la sujeción a un proveedor o a un consumidor particular, máxime cuando la competencia se halla a la orden del día" (Páramo, 2003 14).

14. En el futuro podría ser interesante prestar especial atención a las alianzas matrimoniales que se encuentran hoy en el occidente entre las familias oligarcas. 
Diagrama 4

ENFRENTAMIENTOS ENTRE FAMILIAS LOCALES

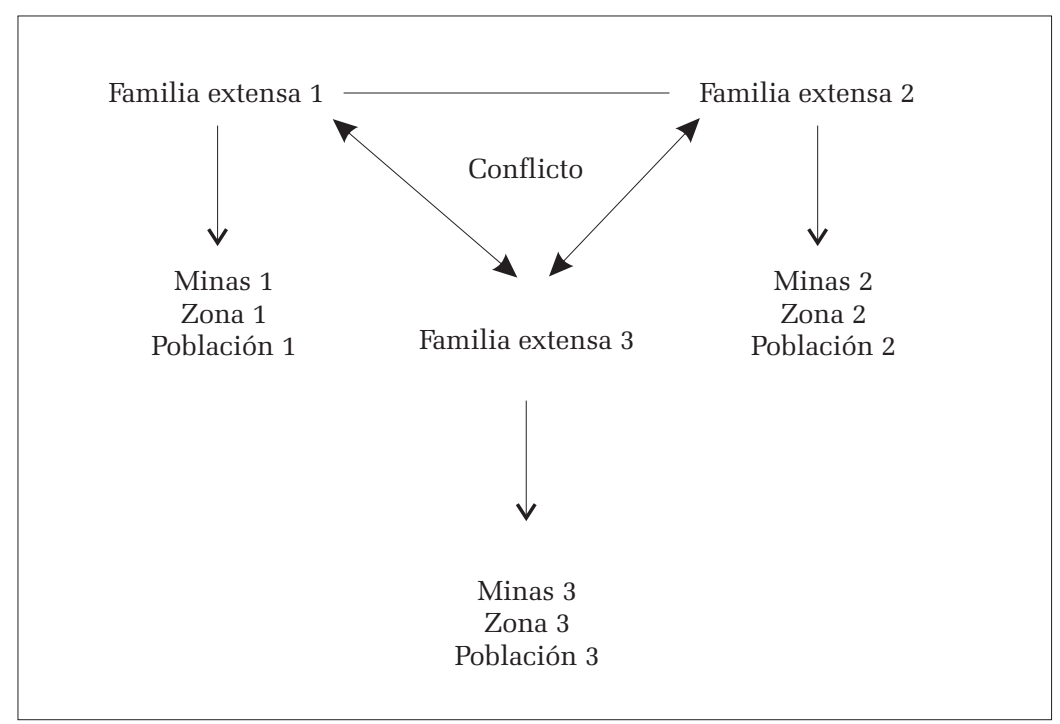

Diagrama 5

ORDEN QUE SURGE DE LA SITUACIÓN POS GUERRA

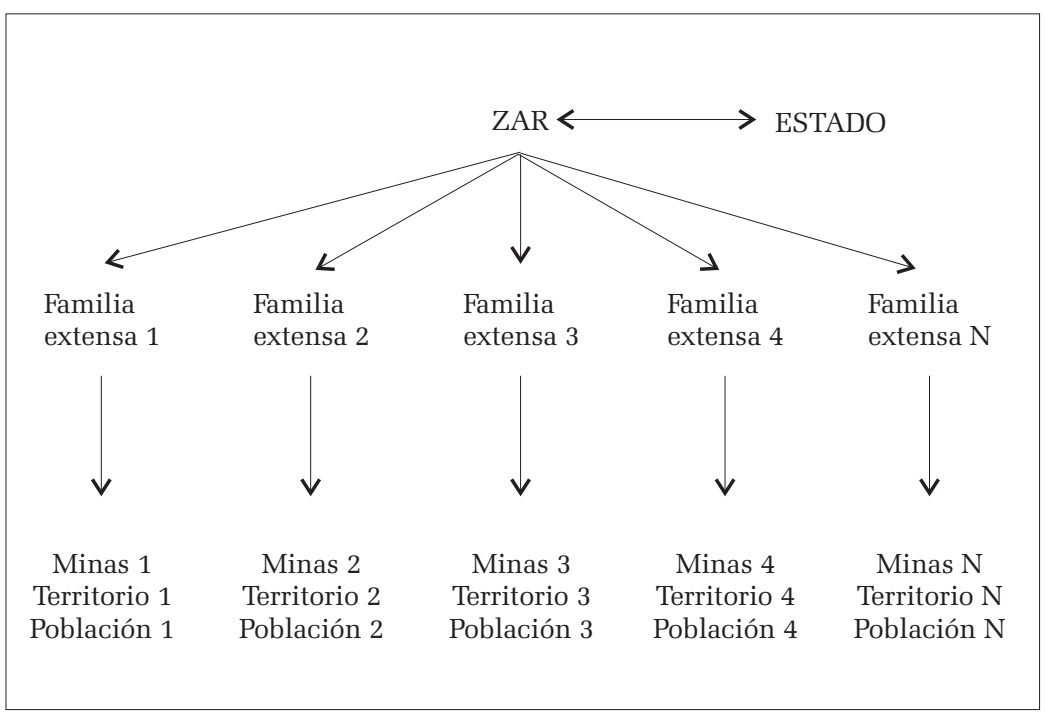




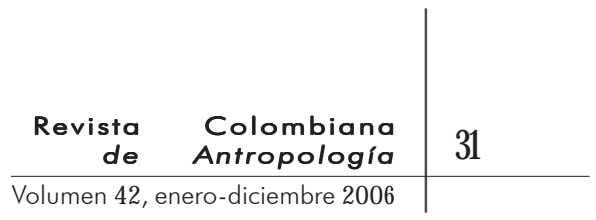

En este orden, aun cuando cada familia centralizada alrededor de un patrón ejerce poder sobre su territorio y monopoliza el trabajo y la producción de las minas que le corresponden, está sometida al poder del zar, supra poder que no se entromete en las decisiones de las localidades, sino que, más bien, coordina la resolución de los conflictos, y, siendo un aliado de otras fuerzas como el estado, por ejemplo, sirve de intermediario de este, dando órdenes a las familias locales. Es muy importante reconocer que el zar no es un hombre que goce de mucho prestigio; es respetado por su poder-económico, político y militar-, pero está alejado de los locales. Por eso, cuando las familias le otorgan poder hay pérdidas momentáneas de poder (Adams, 1983), que podrían explicar la situación actual, en la que hacen presencia diferentes milicias, y han penetrado en el negocio, cada vez más, los dineros ilegales.

\section{Cambios en la familia \\ tras la consolidación de los nuevos poderes y de la nueva economía}

U ASTA LOS AÑOS 1980, EL TRABAJO EN LA MINA SE HACÍA POR EL ANTIGUO I sistema de tambreo o tierra lavada, mediante el cual un buldózer removía la tierra de una roca o parte de una montaña donde se presumía que había esmeraldas, y la arrojaba a una quebrada, en la que se ubicaban los guaqueros para lavar la tierra que caía, antes de que fuera arrastrada por el cauce del agua. En este sistema de explotación era común que participaran hombres, mujeres y hasta niños, por lo que, como en una suerte de prolongación de la unidad doméstica campesina del periodo anterior, muchas familias se trasladaron a esos lugares para trabajar conjuntamente. Las que así lo hicieron permanecieron juntas en la búsqueda de $l a$ piedra, como es usual que se le diga a las esmeraldas en la región, y mantuvieron la presencia del padre en el hogar. Cerca a las minas se desarrolló entonces una suerte de aglomeración de barrios. Los nuevos asentamientos se fueron transformando en inmensas zonas en las que se hacinaban viviendas que se convirtieron en terreno fértil para el desarrollo de una violencia cuyos tentáculos eran la cantidad de hombres armados. La afluencia del dinero circulante generado por la actividad minera condujo al incremento del consumo de alcohol y de la prostitución, prácticas asociadas al comportamiento masculino y que menoscabaron las 


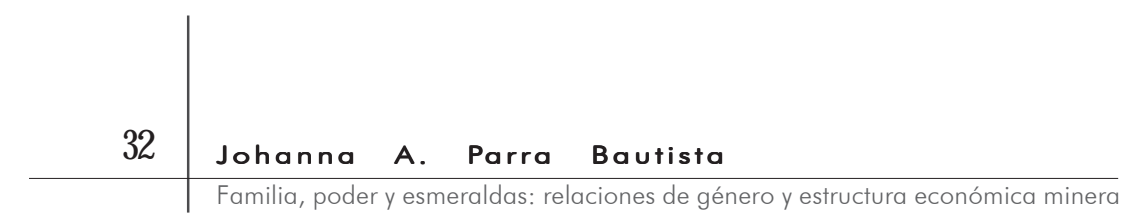

relaciones familiares. El aumento considerable de los índices de violencia contra las mujeres y los niños, y los cambios que hubo en el hogar durante ese periodo permanecen en la memoria viva de muchas mujeres, como en el caso de Blanca, de cuarenta años, que ahora trabaja como empleada del servicio doméstico en Bogotá:

Yo no nací en zona de esmeraldas, soy de tierra fría, pero me conseguí un hombre de allá y me llevó a vivir a Muzo. Los dos guaquiábamos en la quebrada y teníamos una casa en [Caña de Azúcar], de esos barrios que se formaron alrededor de la mina; todavía está por ahí la casita. A ese señor le sufrí de todo: golpes, mozas (amantes). El peor castigo que mi dios le puede dar a uno es esa plaga de por allá. Yo me enteraba de las mozas, hasta lo veía con ellas, pero él me decía que a mí que me importaba eso. Tuve al primer niño y ese señor nos abandonó, después apareció otra vez, y entonces me hizo el segundo niño. Es que uno de mujer es muy bobo. Después ya lo mataron a él y yo me vine a Bogotá y trabajo para sacar adelante a los hijos.

Más temprano que tarde, las mujeres se convirtieron en víctimas del maltrato físico de sus esposos, y muchas debieron hacerse cargo del hogar por sí mismas. No obstante, la jefatura femenina del hogar no siempre fue resultado del abandono: muchas se produjeron por la muerte del esposo en alguna de las olas de violencia que trajeron las guerras, en las peleas en las galleras o en los enfrentamientos entre borrachos. Al conversar con varias de las mujeres que vivieron cerca de las minas en los primeros años del auge de la actividad y que perdieron a sus esposos, sorprende escuchar que cuando conocieron de su muerte sus sentimientos fueron de alivio, o, máxime, de reproche por no haberles dejado algo para sus hijos en vez de haberlo gastado todo en mujeres y alcohol.

15 Entre los mineros no pude encontrar una explicación a la exclusión de las mujeres de este tipo de trabajo. Me llamó la atención, sin embargo, que en el lenguaje minero la veta es una especie de vena blanca, cuya existencia indica la proximidad de las esmeraldas. La veta se considera hembra cuando hay esmeraldas en su seno, y macho cuando no contiene nada. En las minas de plata de Guanajuato, México, está prohibido el ingreso de mujeres, porque según la interpretación popular son unas enormes vaginas que sólo pueden ser penetradas por varones.
Cuando se abandonó el sistema de tambreo se desarrolló la técnica de exploración por túneles, consistente en cavarlos en la montaña, por donde se arrastra apenas un hombre delgado, en busca de la piedra. A este sistema se le denomina también guaquiar, pero a diferencia del guaqueo en la quebrada, en esta nueva modalidad sólo participan hombres $^{15} \mathrm{y}$ algunos niños que logran 


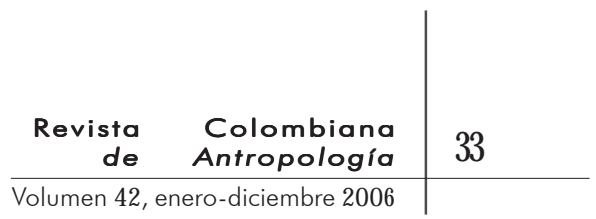

entrar a los túneles clandestinamente, pues el acceso se restringe a los trabajadores adscritos a cada mina.

Entre las familias oligarcas los cambios en las relaciones familiares han ido por otra vía. Como mencioné en la Introducción, las labores de la mina y las dimensiones del negocio para aquellos que empezaban a controlarlo demandaron la disponibilidad de más personas de confianza para atender los dos frentes. Los patrones emergentes suplieron esta necesidad por medio del reagrupamiento de sus parentelas, principalmente masculinas, alrededor de ellos. Así, individuos vinculados a un patrón por lazos de consanguinidad y de afinidad llegaron a ocupar funciones como administradores, controladores $^{16}$, choferes y guardaespaldas. Dejaron atrás sus trabajos en la agricultura o como guaqueros en la mina y se especializaron en oficios de control y supervisión, siempre como subalternos de un patrón. La selección de los parientes como hombres de confianza nos da una idea sobre las construcciones culturales de doble vía de las relaciones de parentesco en la zona: el patrón deposita su confianza en ellos y, así mismo, la

16. Control es el obrero de mayor jerarquía en el trabajo en la mina, pues está encargado de supervisar el trabajo dentro del túnel. Tiene poder porque el patrón o plantero -quien financia la exploración o explotación- deposita en él su confianza. Si llega a haber producción y el patrón no está presente, el control debe detener el avance de la explotación hasta que él llegue. Es un cargo que demanda/ amerita mucha confianza.

fidelidad al patrón les demanda tiempo completo de trabajo: todo el día y toda la noche deben estar a su lado, por lo que terminan viviendo en su casa y convirtiéndose también en sus compañeros de diversión.

En el análisis de los cambios producidos por las actividades mineras en las relaciones familiares se aprecia la centralidad de las construcciones de masculinidad, que en el occidente de Boyacá están en diálogo directo con la economía de la región. De socios de sus mujeres durante el periodo anterior al desarrollo de la explotación de esmeraldas, los varones se convirtieron, muy pronto, en padres ausentes que limitan los momentos de socialización con su núcleo familiar a los almuerzos dominicales, las visitas a la iglesia católica y las eventuales reuniones con la parentela. Sus nuevas actividades y ritmos de vida los transformaron en típicos proveedores de comida, techo y vestido para sus mujeres e hijos.

Ahora bien, el papel de padre es diferente si se trata de un hijo o una hija. Aun cuando las niñas y los niños permanecen 


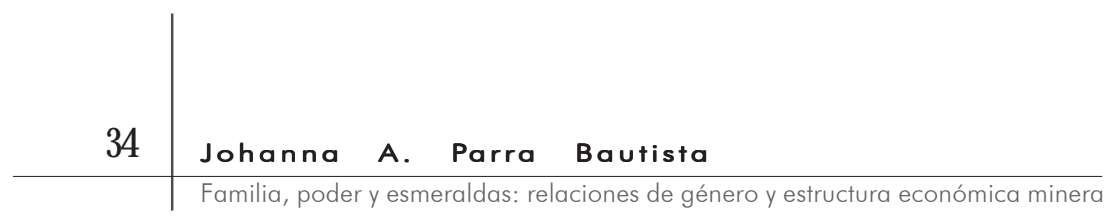

cerca de la madre durante toda la infancia, una vez los varones llegan a tener entre diez y quince años de edad los padres retoman su cuidado para convertirlos en hombres. Comparable a la imagen que ofrece Godelier de los baruya, entre quienes a medida que los hijos crecen "las mujeres están mentalmente separadas (...) de sus poderes de creación. Por el contrario, llegará un día en el que serán desposeídas de sus hijos varones, cuando los hombres vengan a buscarlos para procrearlos de nuevo, para transformarlos en hombres" (Godelier, 1986: 8). En el occidente de Boyacá, antes de que el niño entre a la vida adulta, su padre se encarga de educarlo en los oficios de la mina y, especialmente, en la cultura masculina que se requiere para hacer parte de ese mundo. Así se los sentencia a convertirse en hombres violentos, en pequeños patrones que deben estar familiarizados con todas las manifestaciones del control y el manejo de la violencia. Porque, como lo señala Tovar (2005 191), "si los niños deben ser educados para la guerra, si se les enseña a ser agresivos y a obedecer órdenes desde pequeños, manifestarán un comportamiento violento en todas las áreas de la vida”.

De este modo, una vez los hijos se vuelven adultos, las madres pasan a un lugar subordinado con respecto a ellos. Su subordinación, sin embargo, no es el resultado sólo de un ejercicio de dominación masculina, sino de la aprobación femenina que "comparte las representaciones" que legitiman está dominación (Zárate, 2005 83). En efecto, para las mujeres es muy satisfactorio que su hijo se convierta en un hombre, que herede el poder y el dominio de su padre, aprenda los negocios de la mina y de las

17. Ahora bien, los hijos que heredan el poder del padre no son necesariamente los primogénitos; si son varios, todos se entrenan para ingresar en la categoría de los hombres adultos, y el mejor de ellos, el más hábil en los negocios, el "más verraco», el más audaz, será el nuevo centro de la familia. fincas, trabaje por el negocio minero y aprenda a defender a su familia ${ }^{17}$.

En este juego de enseñanzas al hijo se le trasmite una serie de valores masculinos para resaltar su virilidad: el uso de las armas y del dinero, no sólo como poder adquisitivo o de defensa, sino como elementos de ostentación que ocupan lugares privilegiados en las representaciones del poder de esta sociedad. Sombrero vaquero, camisa estampada o tipo polo, jeans y botas tejanas o tenis de marca constituyen el atuendo masculino típico, que se complementa con dos elementos: el aderezo de oro con incrustaciones de esmeraldas adornadas con diamantes "para resaltar la belleza 


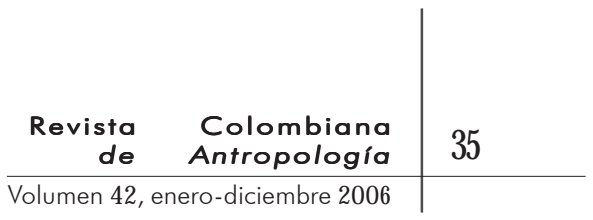

de la joya”, y el arma insustituible: en la región ésta es sinónimo de masculinidad. En su rito de paso a la edad adulta, cada niño/ adolescente obtiene un arma de su padre o protector, como una herencia de masculinidad y de poder para abrirse camino. De manera análoga a la de recibir la raza de su padre en el parecido de sus facciones o en la rudeza para los juegos y el trato con los otros varones, su inscripción en el sexo masculino le define un futuro como guerrero. Esta manifestación tiene su retribución para los padres, pues entre más se parezcan los niños a ellos, más hombría les otorga a estos y mayor orgullo a las madres.

La socialización de las niñas hasta su entrada a la vida adulta continúa en manos maternas. No obstante, a diferencia de lo que sucedía en el contexto campesino, cuando se daba prioridad a los estudios de los varones, en esta nueva situación las niñas continúan por más tiempo la educación. En contra de lo que se podría esperar, a pesar de que las mujeres aprueban un tipo de socialización violenta para los hijos varones, de manera que el niño pueda convertirse en una imagen viva de su progenitor, las mujeres que entrevisté me expresaron sus deseos que sus hijas estudiaran, cambiaran de vida y, sobre todo, no se casaran con hombres de las minas. A pesar de ello, ni las madres ni los padres de las niñas aceptan fácilmente su entrada en la adultez, y las perciben más bien como niñas eternas, no mujeres $^{18}$, lo cual ofrece un contraste fuerte con los hijos varones, iniciados desde muy temprano en la vida sexual, el juego, el alcohol (trago) y el uso de armas.

Por su parte, los hijos de las fa-

18. No se debe perder de vista que esta generación fue socializada dentro de los ideales de la mujer decente, una mujer seria, que no es coqueta, que no siente deseo y menos placer, hecha para la reproducción, la vida doméstica y la conservación de su futura familia. milias que no hacen parte de los círculos del poder local se inscriben en dinámicas menos constreñidas por los límites de la consanguinidad en primer grado. Además del padre, pueden ser socializados por un tío, por el padrino o por un patrón que descubre en ellos un carácter fuerte, es decir, los reflejos de un hombre trabajador, que promete ser fiel y disciplinado frente a su patrón, digno de "un verraco protector". Estos niños y jóvenes elegidos poseen el potencial para alcanzar lugares importantes al lado de un patrón, lo que puede ser sinónimo de movilidad social. Teniendo además suerte en los negocios, pueden llegar a convertirse, incluso, en patrones. Las mujeres, en cambio, llevan un destino marcado por la relación que establezcan con los hombres: si es 


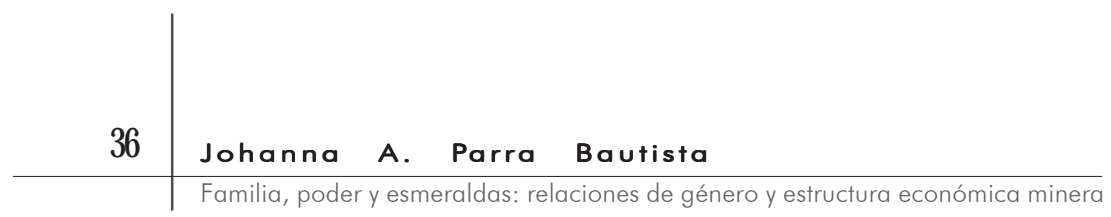

una mujer decente y recatada puede llegar a ser la esposa de un patrón; si es bella y fogosa puede convertirse en su amante. Pero lo irónico es que su lugar en la jerarquía femenina se define por el lugar de los hombres con quienes están relacionadas: su padre, su marido o su amante, así como por la manera como ellos perciben su comportamiento.

Durante el trabajo de campo me llamó la atención que las mujeres casi nunca usan la palabra machismo para definir el comportamiento de los varones, y en particular el de sus maridos. Usan, como lo mencioné, el término dominancia, con el que hacen referencia a la prominencia masculina en diferentes situaciones: I) los hombres son dominantes; 2) siempre creen tener la razón; 3) son violentos; 4) se consideran más importantes que todos. Ahora bien, si uso una de tantas descripciones sobre el tipo ideal de machismo a las características que definen la dominancia, es posible apreciar la proximidad que existe entre uno y otra. Para ello me he valido del tipo ideal del macho que para el caso mexicano ha propuesto Teresa Páramo:

Monopolio del poder; superior a la mujer; el único autorizado en (sic) tomar decisiones importantes de la familia; autoritario; siempre tiene la razón; no tolera ser contradicho; padre ausente; valiente; nunca puede demostrar que siente miedo; fuerte; nunca puede demostrar ser débil; hermético, tiene problemas de comunicación; no deja salir sus sentimientos; no puede mostrar que siente ternura; no puede ni debe llorar; es abusivo; exigente; mandón; es de carácter fuerte; es mujeriego; las mujeres de su vida: madre, esposa e hijas deben ser castas; exige casarse con una mujer virgen; debe ser sexualmente potente; es bebedor y golpeador; se reúne con otros hombres de la familia y no de la familia; debe ser considerado como el proveedor; es brusco; trata a los demás como subordinados; es celoso; es posesivo, etcétera (Páramo, 2005 242-243 Subrayados míos).

Con excepción de "la toma de decisiones importantes para la familia”, este tipo ideal de macho puede aplicarse a las construcciones de la masculinidad en el occidente de Boyacá, porque son justamente las decisiones familiares el campo en el que las mujeres de esa región dominan, gracias a su capacidad para negociar y ser protagonistas en las relaciones íntimas con los hombres. 


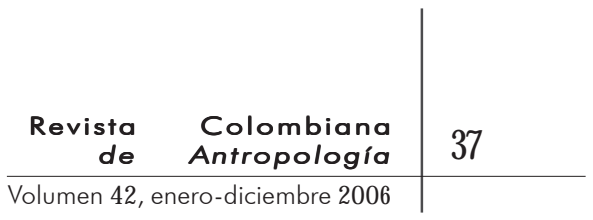

\section{Acceso permanente a la intimidad}

E LOS GRUPOS DE MUJERES QUE TIENEN ACCESO A LA INTIMIDAD SEXUAL con hombres fuertes de las minas y a sus espacios cotidianos -amantes, prostitutas y esposas- me limitaré a examinar el de las esposas, no sólo por cuestiones de extensión sino, sobre todo, porque ellas permiten articular el examen de las relaciones de género con el de las relaciones familiares y la parentela bilateral. No obstante, es indispensable no perder de vista que el prototipo de hombre hermético y dominante del occidente de Boyacá, cada vez más familiarizado con los poderes monetario y militar, es débil frente a la capacidad de despliegue erótico de las amantes y de las prostitutas, por lo que éstas merecerían un análisis detallado.

Las esposas de patrones a las que me referiré se pueden clasificar en dos grupos: el primero está constituido por mujeres que en la actualidad tienen entre cuarenta y cincuenta y cinco años de edad, esposas de patrones que alcanzaron un auge económico considerable a finales de la década de 1980 y comienzos de los años 1990, y migraron a Bogotá en una coyuntura que ligó la buena situación económica de sus maridos con el desenvolvimiento de la segunda guerra entre esmeralderos. El segundo está conformado por la siguiente generación de esposas de patrones y esmeralderos que radican cerca de las minas, mientras ellas se desplazan con sus hijos permanentemente entre alguna ciudad intermedia o la capital donde residen y el lugar de trabajo de sus esposos. Sus edades oscilan entre veinticinco y treinta y nueve años.

\section{LAS SEÑORAS DEL HOGAR: PRIMERA GENERACIÓN DE LÁGRIMAS}

Las esposas y, en un muchos casos, ex esposas de quienes fueron los patrones que recibieron las minas del estado al final de la década de 1970, son mujeres nacidas en el occidente de Boyacá y que proceden de familias de agricultores humildes. En su mayoría, consideran que sus esposos fueron hombres honorables, quienes las elegían como sus esposas gracias a su decencia, virtud que se entiende como resultado de la educación impartida en las familias. Sin embargo, al interrogarlas sobre su niñez, muchas veces encontré referencias a una infancia no muy 


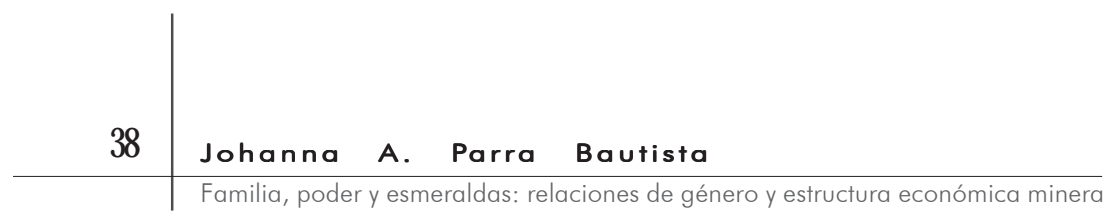

afortunada: habían sido objeto de agresión por parte de su madre y de sus hermanos mayores, hacían todo tipo de trabajos domésticos y sufrían múltiples prohibiciones que les impidieron disfrutar de los juegos y amigos de infancia (Puyana y Orduz, 1998). El siguiente es el relato de la señora María, quien estuvo casada durante dieciocho años con un patrón:

Desde siempre he estado condenada, creo que esté maldita. Mi de malas me la sembró mi mamá con los leñazos que me pegaba a cada rato. Después mi hermano [mayor] que me agarraba a pata cada vez que quería (...) La única que me quería era mi abuelita [paterna], pero ella se murió cuando yo era muy niña. Yo descansaba de los golpes cuando me iba a su rancho. Después conocí a ese señor Antonio, mi ex marido, y me casé con él a los diecisiete años. (...) Yo nunca he sido feliz, creo que me casé porque quería irme de la casa, y con él me fue peor (...).

Casi todas las mujeres de esta generación a quienes pude entrevistar cuentan apenas con escolaridad primaria, muchas veces incompleta. Contrajeron matrimonio entre los catorce y los dieciocho años, siempre por la iglesia católica, y tuvieron sus hijos muy temprano. En todos los casos su esposo fue su primer y único novio; se casaron vírgenes, creyendo ciegamente en la perpetuidad del matrimonio y la unión familiar en que habían sido educadas. Sin embargo, muchas terminaron separándose de sus maridos, y hoy comentan que, a pesar de haber luchado durante décadas por mantener unido el hogar, los dejaron y se divorciaron para mantener su propia dignidad, sin importar si lo hacían a costa de sus propias creencias en el matrimonio, y del reproche y la sanción de su familia y su comunidad. Con el tiempo han ido madurando un discurso sobre los elementos positivos que acarreó su decisión: tranquilidad, defensa de su autoestima y de realizarse como mujeres solas, y una actitud crítica frente al machismo que antes habían defendido. Una cosa continuó intacta: la relación con sus hijos e hijas. La prole, según ellas, es el único logro perdurable de los años de unión con sus esposos.

$\mathrm{Al}$ contrario de ellas, sus ex maridos han vuelto a contraer matrimonio o viven en unión libre con mujeres, por lo general más jóvenes, con las que, además, han vuelto a procrear otros hijos. Mientras que en el caso de las mujeres el divorcio era un asunto de dignidad, para los hombres es uno de dinero, de repartición de bienes y de cuotas para los hijos. 


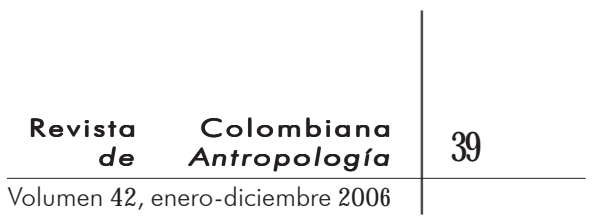

Se podría afirmar que las mujeres de esta generación vivieron el impacto más fuerte del paso a la economía extractiva minera: pasaron de estar sujetas a unos principios familiares que contemplaban servir al marido, visto como un hombre responsable y trabajador, dar amor a los hijos y proveer de alimentos, a ser esposas de hombres poderosos, los dones, y, por tanto, a ser figuras visibles del poderío de ellos. Todo el pueblo las reconocía en la calle, las saludaba y las respetaba. Cuando menos lo imaginaban, el poder económico de sus esposos les permitió acceder a un excedente monetario que, de acuerdo con su nueva posición, debían gastar en lujos, muchas veces suntuosos: joyas, ropa, propiedades, fincas, casas, carros, caballos de paso, ganado, entre otros. Así, visibilizadas en público gracias a su relación con sus esposos, debieron hacer uso, también, de los nuevos capitales simbólicos asociados con su nuevo estatus. Pasaron de un hogar pobre en la infancia a uno rico en la vida adulta.

Por la cuantía de los excedentes que dejaba el negocio de las esmeraldas en esos años, todas las esferas de la vida cotidiana experimentaron numerosos cambios, para hacerla congruente con el auge económico. Uno fue el de la identidad femenina: la mujer sumisa y recatada, descrita al inicio de este apartado, terminó convertida en uno de los pilares de la parentela bilateral que debía servir al don para beneficio de todos. Pero a finales de 1970 las señoras de los hogares de la oligarquía emergente se trasladaron, junto con sus hijos, a las casas que sus esposos compraron en Bogotá, en los barrios tradicionales de esmeralderos, y entonces hubo muchos cambios.

En un comienzo, la mujer permanecía en el hogar, dedicada al cuidado de sus hijos, al tiempo que brindaba ayuda a parientes, frecuentemente hermanos y hermanas solteros por línea materna, ayuda representada por lo general en estudios y alimentación. Mientras, el padre-patrón permanecía largas temporadas en la mina y otras más cortas en el hogar. El hombre se mantenía en movimiento permanente entre la mina y la ciudad, tratando de alejar a su esposa y a sus hijos del ambiente hostil que generaba las guerras de esmeralderos. El diagrama 6ilustra cómo se dividió la parentela unida alrededor de las minas. 


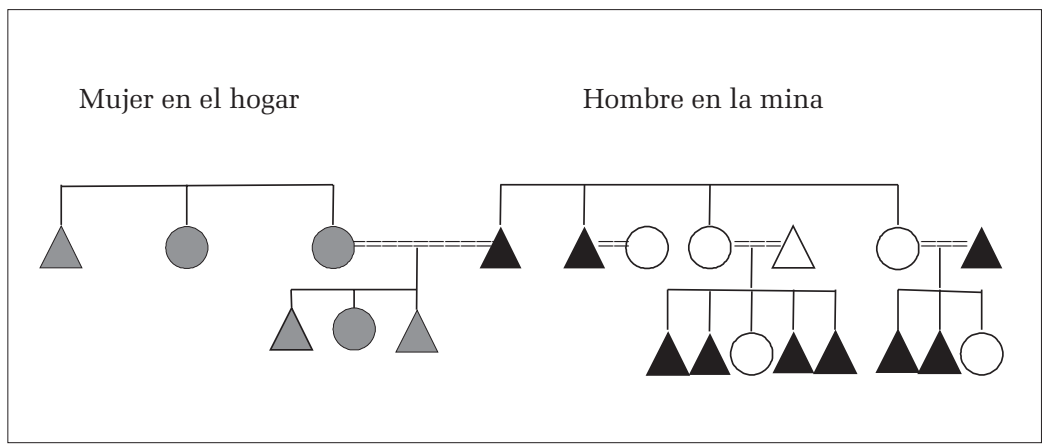

Como se ve en el diagrama, la mujer permanece en el hogar con sus hijos y hermanos. En este caso particular, su hermana le colabora con la crianza de los niños y le sirve de dama de compañía, y el hermano es una suerte de conductor y mandadero; ambos son menores que la mujer. Mientras tanto, el esposo está en la mina junto con su hermano y sus sobrinos, hijos de sus hermanas mayores. En este mismo caso existe mucha confianza entre los dos hermanos que están en la mina, cuestión que fortalece la figura de ambos en la familia extensa. Los sobrinos trabajan como obreros y controladores, a pesar de ser hijos de las hermanas mayores, lo que indica que si alguno de ellos asciende es por sus propios méritos.

Esta separación hogar-minas, que comenzó siendo temporal, se convirtió en una constante durante décadas, con excepciones muy claras en casos tales como el retiro de los hombres de las minas a causa de las guerras, la violencia, la muerte del hombre o la quiebra económica.

La consecuencia más evidente de esta división mujer-ciudad/ hombre-mina es la adaptación de este grupo de mujeres a la vida urbana, con la transformación de la sociabilidad que caracterizaba a sus familias. Por ejemplo, las mujeres de esta generación fueron las únicas que ampliaron sus amistades fuera de la región, criaron a los hijos fuera de esos municipios, diversificaron sus actividades mediante el aprendizaje de nuevos oficios lucrativos -belleza, cocina, tarjetería, floristería, entre otros-. Los hombres, por su parte, cuando se encontraban en la ciudad continuaban en contacto casi exclusivamente con quienes provenían de la zona 


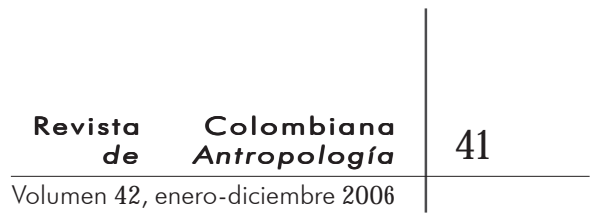

esmeraldífera, tanto para los negocios como para la diversión. A pesar de los cambios que implicó la vida urbana, las mujeres siguieron cumpliendo con su papel de madres y esposas, y fue tal vez el objetivo de hacerlo mejor lo que las llevó a ampliar sus redes, con el aumento consecuente de capital social para ellas y sus hijos. Este cambio explica, en parte, la serie de rupturas conyugales que hubo en esta generación.

Las nuevas experiencias no sólo permitieron que ellas ampliaran sus redes sociales: el tiempo libre del que disponían las llevó a explorar nuevas posibilidades en la educación de sus hijos: la mayoría los educó en colegios privados, que les tendieron un puente hacia su integración en dinámicas urbanas juveniles que los distanciaron de los medios de donde provenían sus familias. Muchos de ellos son profesionales que no han tenido ningún contacto con la zona esmeraldífera ${ }^{19}$, no reconocen el pasado minero de sus padres, y a pocos les interesa la historia materna de su movilidad social.

Convencidos de las ventajas que otorga a sus hijos entrar a la 19. Sin embargo, luego de un sondeo rápido de sus profesiones encontré una inclinación vida profesional, la participación por las carreras relacionadas con el agro. de los padres en su educación se ha orientado a la adquisición de medios materiales: compra de enciclopedias y tecnologías, oferta de viajes y cursos y pago de maestros particulares. El siguiente es un fragmento de una entrevista al señor Rico, de cincuenta y seis años, quien vivió un auge económico importante, pero nunca logró consolidar su fortuna.

\begin{abstract}
Muchos errores he cometido. Podría ser hoy muy rico, tener mínimo un millón de dólares, porque cuando yo empecé en la mina tuve mucha suerte, pero malgasté, era muy joven y me gustaba mucho el juego, tenía mujeres, malgasté. Ojalá hubiera invertido. Eso sí, a mis hijos les di estudio, estudiaron lo que quisieron, ahora que se defiendan porque aquí ya no hay dinero.
\end{abstract}

Para el señor Rico las únicas posibilidades de apoyar a sus hijos son las monetarias, caso que ilustra la sobrevaloración dada por los padres a lo material y la dificultad que tienen para expresar sentimientos, carencia que suplen con los regalos. Este rasgo de masculinidad que les impide expresarse afectivamente por fuera de lo material es más fuerte aún cuando el padre se separa del núcleo familiar y cuando los hijos varones dejan de 


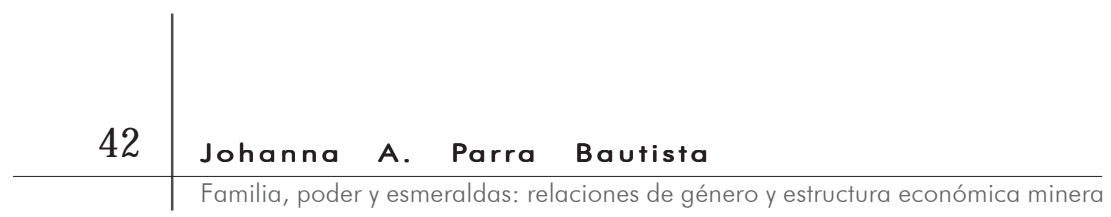

identificarse con sus ideales masculinos. Es así que en muchos casos los padres de esta generación se sienten decepcionados al ver que entre los valores de sus hijos no están la ambición y el poder, que consideran necesarios para hacer fortuna.

Las madres, en cambio, luchando contra su propio pasado como miembros de un hogar en el que no existió el diálogo, establecieron relaciones de confianza mutua con sus hijos, que les permitieron entender las diferencias generacionales y de crianza. Se puede afirmar que lo que ellas les han entregado es un capital social y cultural adquirido en el mercado, que ven como el medio para superar sus propios vacíos educativos y como una manera de invertir los excedentes del auge económico de sus maridos.

\section{LA ESPOSA AUTORITARIA, ELEMENTO UNIFTCADOR DEL PARENTESCO}

No puede decirse que en la mayoría de familias suceda la división de las lateralidades. Entre los casos encontrados quiero resaltar el que ilustra el diagrama 7, en el que hubo un patrón $\not \boldsymbol{~}$ que recibió la concesión de las minas directamente del estado. Una de las particularidades de este caso es que es hijo natural, pero socialmente aceptado por la gran fortuna y prestigio de los que gozó durante años. Sin embargo, en determinado momento su fortuna disminuyó, lo cual coincidió con la desintegración momentánea de la familia, que giraba en torno a él. Años después, su cuñado logró amasar una enorme fortuna que lo ubicó hoy en el lugar de patrón de esta familia. Lo interesante de la unificación de estas dos familias es que la protagonista era la esposa del patrón, una mujer autoritaria que presionaba constantemente a su esposo para que incluyera a sus hermanos y sobrinos en el trabajo familiar. Estructuralmente, esto ocurre porque la cantidad de varones del lado materno es mayor, lo que contrasta con un lado paterno mayoritariamente femenino.

Hoy se presenta como plantero ${ }^{20}$ en la mina de El Paraíso, y su gran fortuna crece por inversiones en finca raíz, ganadería, etcétera, que tiene en la región cundiboyacense. El poder económico que posee reunificó a una familia ya fracturada por di-

20. Plantero es quien pone la inversión ecovorcios y nuevas uniones. Su nómica para una exploración minera. esposa es el eje de unión entre ambas familias, porque es la 
DiAGRAMA 7

RELACIÓN DE PARENTESCO Y POSICIÓN SOCIOECONÓMICA. PRODUCCIÓN Y FAMILIA

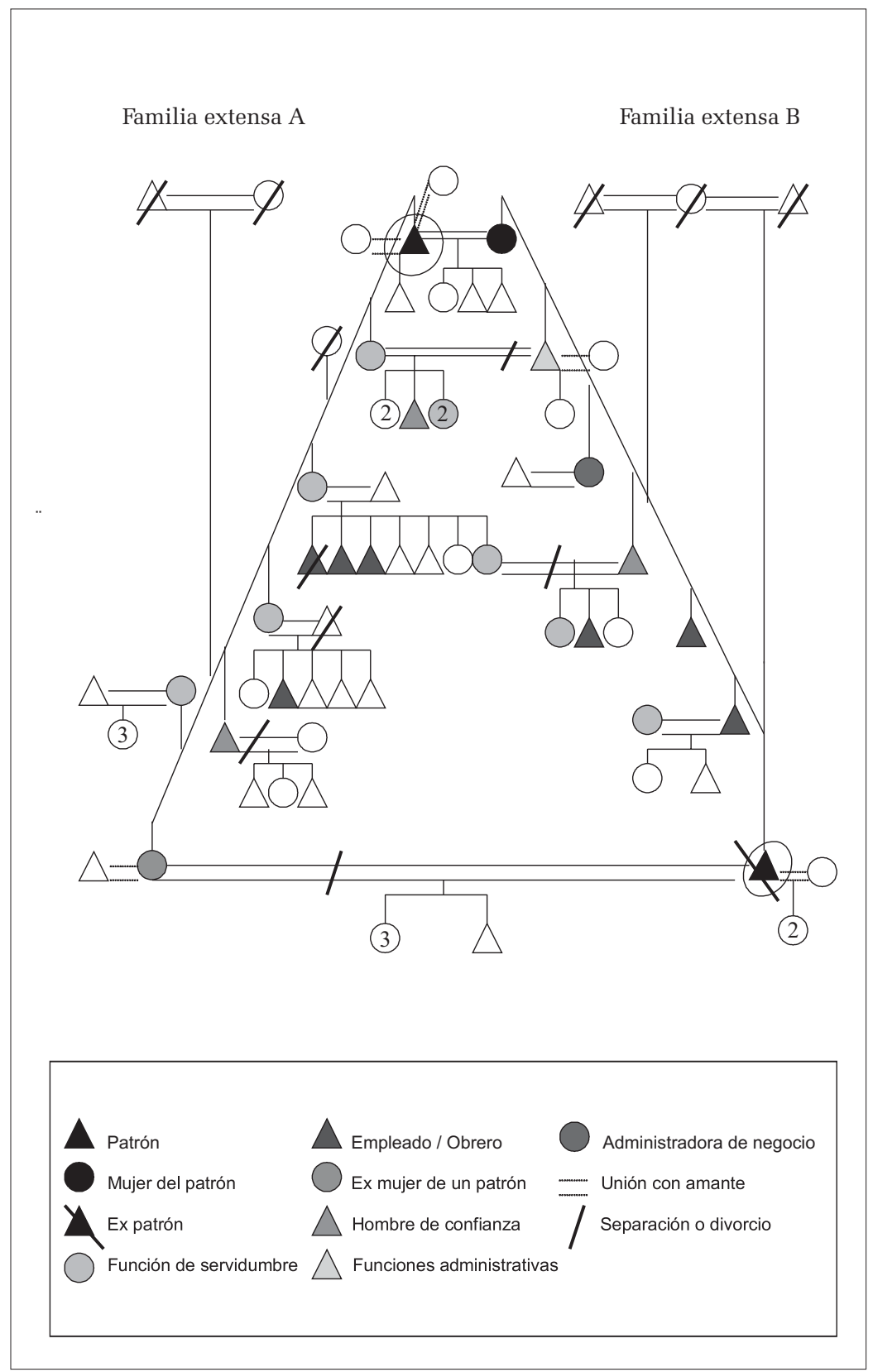




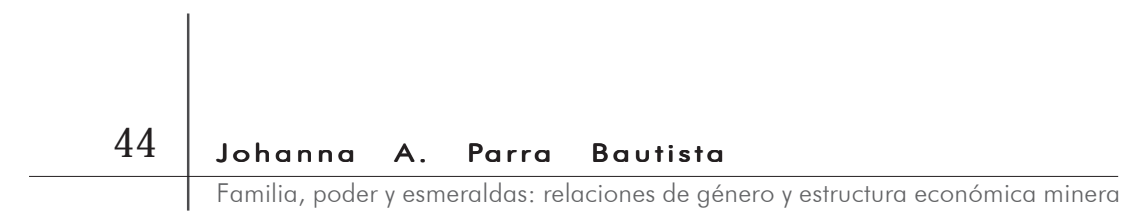

mediadora en la contratación de servicios y se encargó de que todos sus hermanos reemplacen a los hombres carentes en la lateralidad masculina, y sean un instrumento para mantener vigilada y controlada la economía familiar. Se repite el tipo de relaciones, explicados en la Introducción, entre hombres de servidumbre y el patrón, en la que se rompen los vínculos de consanguinidad con la mujer para responder a la jerarquía del patrón. El patrón tiene el monopolio absoluto de las relaciones y de las subordinaciones.

No obstante, las mujeres del diagrama 7 que hacen parte de la lateralidad masculina aparecen en oficios de servidumbre: la cocina, el cuidado de los hijos del patrón e, incluso, los oficios de limpieza. Estas mujeres están relegadas por la esposa del patrón, quien las trata como empleadas domésticas. Su influencia en la definición de la jerarquía es clara. Esta es una de las incidencias en las que se puede ver el control femenino en acción: no es ella quien toma la decisión, pero es capaz de persuadir a su marido de que contrate a su parentela, de que su hermana tenga un rol administrativo que la ponga sobre las otras mujeres de la familia extensa. En entrevista con algunos de los miembros femeninos del lado paterno, las mujeres caracterizaron a la esposa del patrón, su cuñada, como una mujer "manipuladora y envidiosa que no desea que el patrón, su hermano, ayude a nadie a salir adelante".

Estas desigualdades dentro de las familias, marcadas por el estatus y el parentesco, dificultan las relaciones familiares y las vuelven violentas en momentos de crisis. En estas familias el pariente se aprecia o se odia, y los encuentros suelen estar llenos de intrigas y tensión. No es raro que entre familiares haya habido enfrentamientos armados.

En el diagrama 7 se destaca otro elemento: las cuatro uniones habidas entre la familia A y la B. Aun cuando sólo se mantiene la unión del patrón con su esposa, la parentela se fortaleció por otras tres uniones, que hoy ya no existen porque hubo divorcios. La primera unión fue la del ex patrón, que a la vez fue la primera ruptura. Una de las uniones es muy interesante, porque muestra el matrimonio entre un tío político y una sobrina, que según la consanguinidad no indica el incesto, pero algunos familiares sí la ven así simbólicamente.

En esta generación de mujeres se observa la sumisión al poder masculino, que las confinó a largos matrimonios calificados por ellas como infelices. Hay que señalar que ellas participan de 


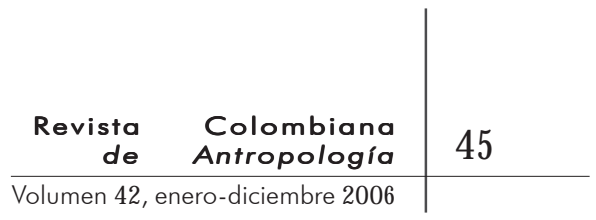

ese poder como subordinadas, y que lo compartieron en diferentes episodios porque tuvieron un nivel más alto entre los dominados, por el respeto que denota ser la esposa de un patrón y, más aún, la madre de sus hijos. Algunas de esas mujeres desempeñaron papeles de dominadoras de otros subordinados, de sus empleados o, en el caso del diagrama 7, esta mujer domina cruelmente a su parentela femenina. Recordemos que

la dominación más eficiente es la que se apoya en miembros del grupo subyugado (...); hacen circular el poder que los domina y se envisten de él, convirtiéndose en cómplices de su propia dominación al hacer uso de los discursos y las prácticas que la justifican y perpetúan (Castellanos, 2005: 45).

Sin embargo, algunas de estas mujeres lograron el control de sus hijos y moldearon para ellos un capital que hoy los mantiene fuera de la guerra y de los negocios de su padre. Aquí vemos que el control de los hijos triunfó, aun cuando el contexto es el de un padre ausente por el trabajo en las minas y un entorno urbano nuevo. Sólo en las familias que perpetúan hasta el día de hoy su poderío los padres insertan a sus hijos, no directamente, en el negocio, sino más bien en ciertas prácticas de violencia y consumo.

\section{Las nuevas señoras: segunda generación de infidelidad, lágrimas y violencia}

A NTES DE AHONDAR EN ESTE GRUPO DE MUJERES, QUIERO RESALTAR QUE el nuevo contexto del occidente de Boyacá pasa por la vinculación de los poderes locales con grupos armados y economías ilegales -paramilitarismo-, que unifica a los señores de esta región para la reconformación del poder, situación que está en proceso. Estos ambientes fortalecen el sentimiento de pertenencia a, y la permanencia en los municipios mineros. La "identidad minera" incluye el estigma social, como lo entiende Goffman (1970), es decir, como la marca que distingue a quien viola una norma propia del orden social establecido. En otras palabras, el estigma social es más fuerte para los patrones de esta generación, porque se asienta sobre la violencia de periodos anteriores -dos guerras- y una población minera cada vez más armada. En 


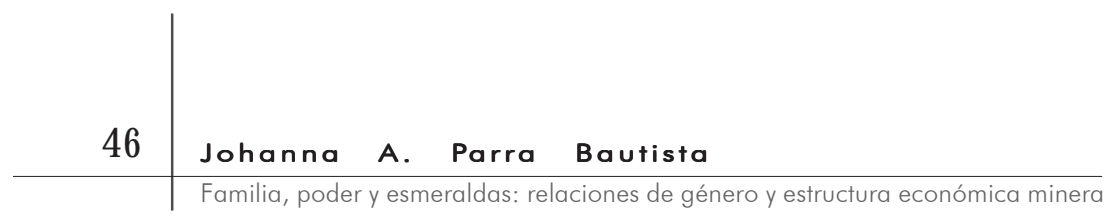

parte, esta es una de las razones por la que estos patrones prefieren permanecer en sus lugares de dominio en vez de salir a las ciudades.

La permanencia de los hombres en el occidente de Boyacá hace que las mujeres y los hijos sean quienes deban desplazarse, situación que impide a las esposas de esos patrones ampliar sus redes sociales, como lo hicieron las del grupo anterior. Permanecen entonces de lunes a viernes en sus hogares en las ciudades y los fines de semana se trasladan a la región para estar en familia. En la ciudad se mueven entre una red heredada en gran parte de las mujeres del grupo anterior. No obstante, esta situación de movilidad las lleva a seguir arraigadas a la vida de los pueblos y a que sus hijos hereden directamente una cultura de la que ellos son protagonistas, por representar a los herederos del poder.

Este grupo de mujeres tiene familia-hermanos, padres, primos, tíos- en los municipios. Cuando están en la región se instalan en las haciendas, donde sus hijos gozan de muchos privilegios: juegos, animales, piscinas, guardaespaldas y una extensa parentela que les sirve. Para irse entrenando en el arte del poder, desde niños, los varones, pero también las mujeres, van desarrollando una voz de mando. Esta superioridad se aprecia fácilmente en las relaciones de las hijas de un patrón con sus primas de edades similares. Los hijos e hijas del patrón tienen acceso a bienes de todo tipo, superior al de cualquier otro niña o niño de la familia y de la región. Esta posición se despliega en la ropa y los juegos a que tienen acceso, y con el pasar de los años se reflejará en objetos tan codiciados como carros, propiedades y armas.

$\mathrm{Al}$ igual que sus hijos, estas mujeres hacen parte de una sociedad consumista de belleza y lujos, en la que ellas mismas son un objeto de lujo para sus maridos. No son sólo madres de sus hijos, son también parte de la apariencia de la "fase familiar" en que se encuentran estos patrones. Usan un erotismo que se alimenta de la capacidad de seducción de sus maridos y de la competencia con mujeres por su belleza. Son las estrellas de los eventos sociales en los pueblos, en donde difícilmente pasan desapercibidas: sus curvas acentuadas y moldeadas con ropa ajustada, jeans, sandalias coquetas, profundos escotes y maquillaje. En su mayoría se han sometido a cirugías estéticas y liposucciones.

En contraste con las señoras del grupo anterior, se atreven a hablar más abiertamente de sus problemas de pareja y de su 


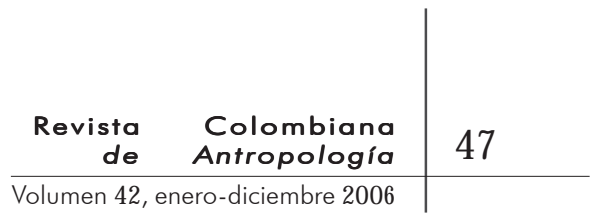

sexualidad. Varias me manifestaron que se enamoraron de sus hombres sólo en el momento de hacer efectivas sus uniones. Sus comportamientos son tan contradictorios que dificultan el análisis de las relaciones entre géneros. Pero aun cuando muchas dicen haber amado a sus esposos, hoy la mayoría reconoce que sólo están a su lado para defender su futuro patrimonial, constantemente acechado por las amantes de sus maridos.

Las amantes desempeñan un papel fundamental en el comportamiento normativo de la masculinidad en el occidente de Boyacá. Si bien se reconoce a la mujer que vive con el patrón como la legítima, este siempre cuenta, mínimo, con una amante, que asume roles complementarios al de las esposas (Gutiérrez de Pineda, 1999). Las amantes no sólo tienen acceso a la intimidad de los patrones, a su diversión sexual, sino también al patrimonio, porque en su mayoría tienen hijos con ellos. De allí que entre esposas y amantes surja una rivalidad violenta. Veamos el siguiente relato de la esposa de un patrón que ejerce poder en la actualidad:

\begin{abstract}
A mí me avisaron que él estaba en la discoteca bailando con una vagabunda (...) Yo cogí mi revolver, uno que él me regaló, y me fui a matarla. Llegué y le hice unos disparos, pero no le di ni a él ni a la hijueputa esa. Después tuve que salir corriendo porque él me persiguió con el revolver dél [sic] para darme cachazos. Yo me escondí en el monte unos días hasta que se calmó.
\end{abstract}

Este fragmento de su relato ilustra el tipo de reacciones violentas que provoca la infidelidad. Cuando ella dice "A mí me avisaron" es obvio que hubo un intermediario que le llevó el chisme a la interesada. Esta forma de control social que se ejerce por medio del chisme ocurre a diario en esos pueblos; sin embargo, se diferencia del chisme que "pone en boca de todos las críticas de una trasgresión cultural, sin que nadie se responsabilice por la misma” (Medrano y Villar, 1988: 26), puesto que su objetivo es contribuir a crear un conflicto en la pareja afectada por la infidelidad masculina, que contradictoriamente es un valor socialmente aceptado en el occidente de Boyacá. Tal es el caso, por lo cual la afectada reconoce que su marido “(...) estaba bailando en la discoteca con una vagabunda”, es decir, en un espacio público. Así, se entiende que en las entrevistas con algunas personeras municipales ellas se refirieran a esos casos con 


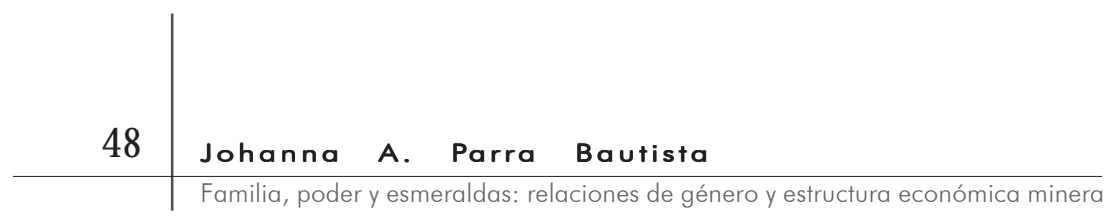

frases como "ellos son infieles por naturaleza". Otro elemento que es importante resaltar de este relato es la referencia al arma utilizada por la ofendida. Cuando dice "Yo cogí mi revolver, uno que él me regaló y me fui a matarla”, se refiere a un revolver que le regaló su marido y que ella utilizará para atentar contra él y su amante. Este intercambio y donación de armas entre esposos evidencia cuán incrustada está la violencia en la intimidad de las familias: para su protección el hombre le ofrece a su mujer un arma, es decir, una invitación a matar a quien le haga mal, y en esta invitación parece no haber restricción alguna.

Este no es un caso aislado en el que los celos y el odio llevan a algunas de estas mujeres a usar armas; al contrario, la situación es corriente, puesto que tienen acceso a estas permanentemente, porque en el hogar las hay disponibles para quienes las quieran. Escogí este testimonio porque a mi manera de ver constituye una evidencia etnográfica de la extensión de este tipo de respuestas violentas entre sujetos en posición subordinada, como es el caso de las mujeres. Lo que es novedoso en él es que demuestra el uso de un mecanismo violento y el de un artefacto que hasta esta generación era esencialmente de uso masculino. La mujer del relato rebasa las posibilidades de control mediante la persuasión, y atraviesa un umbral de acción que antes era exclusivo de los hombres: el uso de armas. El siguiente testimonio, de un habitante de El Embudo, expresa las dimensiones de esta nueva situación. Al comentarme el incidente de una mujer legítima que se enteró de la existencia de la joven amante de su marido (diecisiete años), esto fue lo que añadió:

Esa señora cuando se enteró de quién era la moza del marido se puso bravísima. Fue y contrató unos tipos para que la mataran, y así fue. La buscaron en la casa y la mataron y era una pelada jovencita. Pero eso sí, ¿quién la mandaba a meterse con un casado? El marido de esa señora echaba mientes de la rabia, pero no dejó que encanaran a su mujer. A todas esas vagabundas deberían acabarlas así.

En su relato mi entrevistado aprueba este tipo de violencia como una manera de solidaridad con las mujeres víctimas de la infidelidad. De ahí el significado del calificativo "bravísima" con el que describe la furia de la mujer, con el cual, al mismo tiempo, denota su valentía en el intento por destruir a la joven amante de su esposo. La aprobación de estas conductas femeninas por 


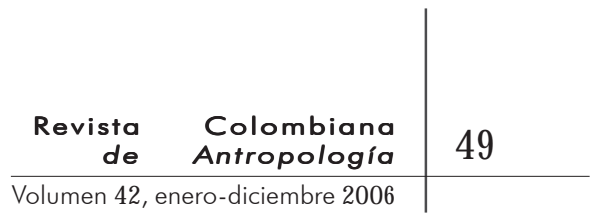

parte de la comunidad es preocupante, en la medida en que su ocurrencia enriquece las nociones populares de naturalización de la violencia. Así, muchos de los habitantes de la región consideran que antes que demostrar la pérdida del valor de la vida, los asesinatos ejecutados por las mujeres, por celos, son una expresión de que ellas "también llevan la violencia en la sangre”, por lo que en esos momentos abandonan su feminidad y delicadeza y se invisten de la agresividad y la grosería masculina. Esos mecanismos ocultos del poder con tentáculos de violencia hacen muy complejas las relaciones sociales de la región, desde la vida íntima en los hogares hasta la vida política de los municipios.

Por un lado, es difícil comprender cómo incursionan las amantes en la vida de las familias y la rivalidad que establecen con las esposas, cuando en la región existe la aprobación social de la infidelidad masculina. Para ello es necesario no perder de vista que estas relaciones se presentan en un contexto más amplio, en el que el incremento de la violencia ha ido de la mano de la supervaloración de los bienes materiales que puede adquirir el dinero, en el que se traducen los excedentes económicos de la región. Por otro, es necesario señalar que todos los hijos de un patrón heredan poder en mayor o menor medida, independientemente de la madre, y que este poder heredado depende en gran parte de las cualidades y competencias que como hombre desarrolle el niño para acrecentarlo.

La trayectoria de las mujeres de la primera generación, denominadas aquí las señoras del hogar, contrasta por completo con la de las esposas actuales. Las primeras desarrollaron mecanismos de adaptación a las nuevas condiciones, basadas en la defensa de su actividad en la finca, que las diferenció radicalmente de los hombres. Las segundas, en cambio, adoptaron mecanismos de defensa consistentes en la prolongación de la violencia masculina. La masculinidad, mientras tanto, ha evolucionado hacia la valoración de una suerte de poligamia que les permite a los hombres la ostentación y, sobre todo, el control directo de una diversidad de negocios por medio de linajes de parentesco en los que son el centro. 


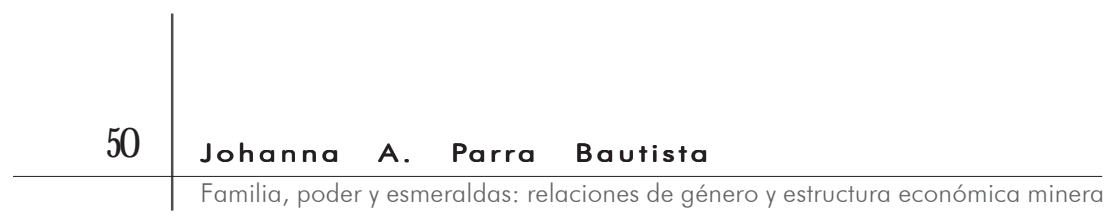

\section{CONClusiones}

N El CONTEXTO DE LOS CAMBIOS ECONÓMICOS OCURRIDOS EN LA SO- ciedad del occidente de Boyacá se observan diferentes moL mentos de la adaptación de la unidad doméstica. Cuando se pasó de una economía agrícola a una de explotación minera de esmeraldas, las familias campesinas se adaptaron por medio del trabajo familiar en el guaqueo. Las familias oligarcas emergentes, por su parte, reunificaron la parentela para el trabajo de vigilancia y control mediante relaciones de confianza afianzadas y reguladas por la consanguinidad.

Entre estas adaptaciones de las estructuras de parentesco y de las unidades domésticas el varón expande su parentela para el control eficiente de "su" territorio, porque implica el control de un recurso significativo. El hombre-poderoso es el centro de estas estructuras y su influencia se sobrepone a la consanguinidad de la familia extensa con su esposa. Esto denota la continuidad de la dominación masculina como elemento estructural.

En los casos estudiados vimos una primera generación de mujeres que creó un ambiente paralelo para ella y sus hijos; fue ella quien controló el desarrollo y la crianza de su familia, pero sólo pudo hacerlo por la ausencia del hombre en el hogar y por las limitaciones de una masculinidad machista que les impide relacionarse de manera afectiva con los hijos. En la segunda generación estudiada la estructura obligó a las mujeres y a los hijos a permanecer en los municipios de la región. En este caso no se crearon nuevos capitales para la crianza, sino que se afianzaron los elementos de materialidad y violencia estructurales del occidente de Boyacá, que sumergen a la mujer y a los hijos en sus dinámicas.

En ambos casos se acentúa una poligamia socialmente aceptada, mediante la cual el hombre expande una parentela que incrementa su virilidad y, al mismo tiempo, le permite controlar más su territorio. Se ve un matiz claro de matrifocalidad, por medio del control que ejerce la mujer sobre la vida en el hogar, que crea tensiones intergeneracionales y de género en la crianza de los hijos.

Los nuevos elementos que se presentan en la región ponen en relación a estas familias con economías ilegales y ejércitos informales, que acrecientan la tendencia al endoculturalismo y a la socialización de los niños en una cultura de la violencia. 


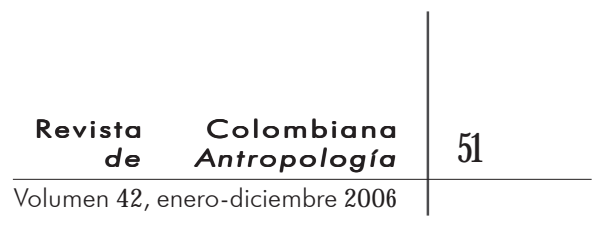

Matizadas, estas características podrían encontrarse en otro tipo de economías regionales del país. Lo desalentador de estos hallazgos es que vemos que la violencia toma un lugar en la crianza y en las relaciones familiares y de género, y los efectos de auges económicos descontrolados y la ausencia del estado como causantes de violencias culturalmente aceptadas.

\section{BibliografíA}

AdAms, Richard. 1983 Energía y estructura. Una teoría del poder social. Fondo de Cultura Económica. México.

Betancourt, Darío y Martha L. García. 1994. Contrabandistas, marimberos y mafiosos. Historia social de la mafia colombiana (1965 1992). Tercer Mundo Editores. Bogotá.

Blok, Antón. 2001 Honour and violence. Polity Press. Cambridge.

1974. The mafia of a Sicilian village 1860-1960. A study of violent peasant entrepreneurs. Harper Torchbooks. Nueva York.

Bourdieu, Pierre. 2000. Les structures sociales de l'économie. Éditions du Seuil. París.

- 1998 La domination masculine. Éditions du Seuil. París.

Castellanos Llanos, Gabriela. 2005 "Sexo, género y feminismo: tres categorías en pugna”. En Patricia Tovar Rojas (ed.). Familia, género y antropología. Desafíos y transformaciones. Instituto Colombiano de Antropología e Historia (Icanh). Bogotá.

"Esmeralderos y empresarios de Boyacá presentarán programa de erradicación de cultivos ilícitos". El Tiempo. Bogotá. 18 de abril de 2004.

FAUR, ELEONOR. 2004. Masculinidades y desarrollo social. Las relaciones de género desde la perspectiva de los hombres. Arango Editores, Unicef. Bogotá.

García SuÁrez, Carlos Iván. 2004. Hacerse mujeres, hacerse hombres. Dispositivos pedagógicos de género. Siglo del Hombre Editores, Universidad Central-DIUC, Consejería Presidencia para la Equidad de la Mujer, PNUD, Casa de la Mujer. Bogotá.

Godelier, Maurice. 1986. La producción de grandes hombres. Poder y dominación masculina entre los baruya de Nueva Guinea. Akal. Madrid.

Goffman, Edwin. 1970. Estigma. La identidad deteriorada. Amorrortu. Buenos Aires. 


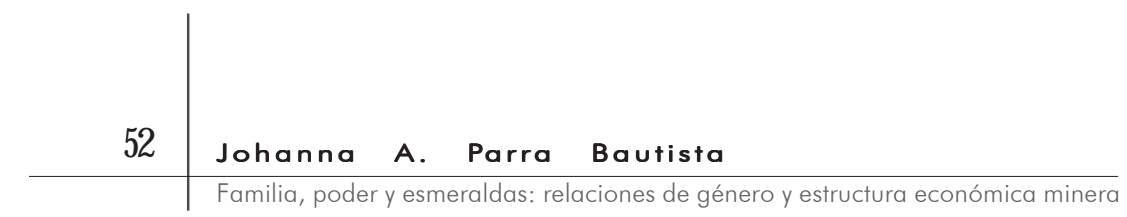

GutiÉRREZ de Pineda, Virginia. 1999. "La dotación cualitativa de los géneros para su estatus-función”. Nómadas. 끄 Fundación Universidad Central, Departamento de investigaciones. Bogotá.

Héritier, Françoise. 1999. "Fécondité et stérilité. Au cœur de la toile idéologique”. Masculin/Féminin. La pensée de la différence. Éditions Odile Jacob. París.

Horkheimer, Max. 1974. Teoría crítica. Amorrortu Editores. Buenos Aires.Informes de United Nations, Office of Drugs and Crime, http:/ /www.unodc.org/pdf/colombia/simci/BOYACA.pdf, consultado el 2 de enero de 2006.

La Nota. http://www.lanota.com/perfiles/?id=99\&pais=co, consultado el 15de abril de 2005

MEdRano, Diana y Rodrigo VilLar. 1988. Mujer campesina y organización rural en Colombia. Cerec, Universidad de Los Andes. Bogotá.

Osorio Pérez, Flor Edilma. 1994, "La jefatura femenina de hogar en zonas rurales de violencia”. Cuadernos de Desarrollo Rural. 32.

Osorio Pérez, Flor Edilma, Olga Lucía CAstillo Ospina et al. 1993 "Jefatura femenina de hogar en Muzo. Entre esmeraldas, pobreza y azar". Avances. 4. Pontificia Universidad Javeriana, Instituto de Estudios Rurales, Facultad de Ciencias Económicas y Administrativas. Bogotá.

PÁramo, Carlos. 2003 "La palabra empeñada: un excurso sobre su uso entre los esmeralderos y los narcotraficantes". Inédito hasta 2003

PÁramo, Teresa. 2005 “Cultura machista e identidad social”. En Rafael Montesinos (coord.). Masculinidades emergentes. Universidad Autónoma Metropolitana. México.

Puyana, Yolanda V. y Cristina Orduz. 1998. "Que mis hijas no sufran lo que yo sufrí”. En Luz Gabriela Arango y Daniel Ramos (coord.). Mujeres, hombres y cambio social. Universidad Nacional de Colombia, Facultad de Ciencias Humanas, Centro de Estudios Sociales. Bogotá.

Rosaldo, Michelle y Louise Lamphere (eds.). 1974. Woman, culture and society. Stanford University Press. Stanford.

Scotт, JoAn. 1990. "El género, una categoría útil para el análisis histórico". En James Amelang et al. (eds.). Historia y género: las mujeres en la Europa moderna contemporánea. Ediciones Alfonso el Magnánim. Valencia.

Steiner, Claudia. 12 de abril 2003 Emeralds and Weapons. Conferencia The Crisis of Legitimate Authority in Colombia. Northwestern University, Chicago.

Sierra, Julieta Aidée. 2003 "Las familias micro empresarias de la industria del vestido en Moroleón y Uriangato, Guanajuato”. Tesis 


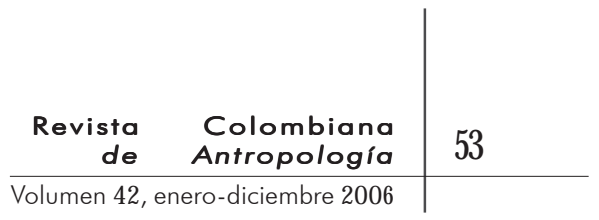

para optar por el grado de maestra en antropología social. Centro de Estudios Superiores de Antropología Social. México.

Téllez Claver, Pedro. 1987. Crónicas de la vida bandolera. Editorial Planeta. Bogotá.

Tovar Rojas, Patricia. 2005 Familia, género y antropología. Desafíos y transformaciones. Instituto Colombiano de Antropología e Historia (Icanh). Bogotá.

. 2005 "La familia en tiempos de guerra y la guerra dentro de la familia". En Patricia Tovar Rojas (ed.). Familia, género y antropología. Desafíos y transformaciones. Instituto Colombiano de Antropología e Historia (Icanh). Bogotá.

Uribe, María Victoria. 1992. Limpiar la Tierra. Guerra y poder entre esmeralderos. Cinep. Bogotá.

VARELA, RoBerto. 2005 Cultura y poder. Una visión antropológica para el análisis de la cultura política. Universidad Autónoma Metropolitana, Unidad Iztapalapa. México.

- 1983 Expansión de sistemas y relaciones de poder. Universidad Autónoma Metropolitana. México.

Viveros Vigoya, Mara y Gloria Garay Ariza. 1999. Cuerpo, diferencias y desigualdades. Universidad Nacional de Colombia, Facultad de Ciencias Humanas, Centro de Estudios Sociales. Bogotá.

Wolf, ERIC R. 1980. "Relaciones de parentesco, de amistad y de patronazgo en las sociedades complejas". En Antropología social de las sociedades complejas. Alianza Editorial. Madrid.

ZÁrate Vidal, Margarita. 2005 "Cuerpos, masculinidades y antropología”. En Rafael Montesinos (coord.). Masculinidades emergentes. Universidad Autónoma Metropolitana. México.

Recibido: 3de enero de 2006.

Aprobado: 28de junio de 2006. 